\title{
Individual differences influence two-digit number processing, but not their analog magnitude processing: a large-scale online study
}

\author{
Stefan Huber ${ }^{1} \cdot$ Hans-Christoph Nuerk ${ }^{1,2,3} \cdot$ Ulf-Dietrich Reips ${ }^{4} \cdot$ Mojtaba Soltanlou $^{1,2,3}$
}

\begin{abstract}
Symbolic magnitude comparison is one of the most well-studied cognitive processes in research on numerical cognition. However, while the cognitive mechanisms of symbolic magnitude processing have been intensively studied, previous studies have paid less attention to individual differences influencing symbolic magnitude comparison. Employing a two-digit number comparison task in an online setting, we replicated previous effects, including the distance effect, the unit-decade compatibility effect, and the effect of cognitive control on the adaptation to filler items, in a large-scale study in 452 adults. Additionally, we observed that the most influential individual differences were participants' first language, time spent playing computer games and gender, followed by reported alcohol consumption, age and mathematical ability. Participants who used a first language with a left-to-right reading/writing direction were faster than those who read and wrote in the right-to-left direction. Reported playing time for computer games was correlated with faster reaction times. Female participants showed slower reaction times and a larger unit-decade compatibility effect than male participants. Participants who reported never consuming alcohol showed overall slower response times than others. Older participants were slower, but more accurate. Finally, higher grades in mathematics were associated with faster reaction times. We conclude that typical experiments on numerical cognition that employ a keyboard as an input device can also be run in an online setting. Moreover, while individual differences have no influence on domain-specific magnitude processing_apart from age, which increases the decade distance effect - they generally influence performance on a two-digit number comparison task.
\end{abstract}

\section{Introduction}

Symbolic magnitude comparison is one of the most thoroughly studied cognitive processes in the field of numerical cognition, and magnitude comparison tasks are very commonly used to study the magnitude processing of symbolic numbers. These tasks are fundamentally twochoice reaction time tasks involving binary decisionmaking. A Google search in May 2016 using the search terms "digit" and "magnitude comparison" revealed more

Mojtaba Soltanlou

mojtaba.soltanlou@uni-tuebingen.de

1 Leibniz-Institut für Wissensmedien, Tuebingen, Germany

2 Department of Psychology, University of Tuebingen, Tuebingen, Germany

3 LEAD Graduate School \& Research Network, University of Tuebingen, Tuebingen, Germany

4 Department of Psychology, University of Konstanz, Konstanz, Germany than 2000 hits. Moreover, the seminal paper by Moyer and Landauer (1967) on symbolic magnitude comparison has been cited more than 1600 times. It has been argued that proficiency in symbolic magnitude processing is an important precursor for more advanced mathematical competence (for a recent review, see De Smedt, Noël, Gilmore, \& Ansari, 2013; for a meta-analysis, see Schneider et al., 2016). Symbolic numbers not only play an important role when learning mathematics, but are also relevant in daily life, for instance, when buying a product (e.g., Thomas \& Morwitz, 2005). Proficiency in comparing numbers varies with the distance effect. The seminal paper by Moyer and Landauer (1967) showed that the performance on a symbolic comparison task depends on the distance between the numbers. The distance effect predicts faster response times and higher accuracy when two numbers with a large absolute difference are compared (e.g., 1 and 6) as opposed to those with a small absolute difference (e.g., 3 and 4). The distance effect occurs in single-digit magnitude comparison tasks as well as in multi-digit magnitude comparison tasks (e.g., Dehaene, Dupoux, \& Mehler, 1990; Hinrichs, 
Berie, \& Mosell, 1982; Hinrichs, Yurko, \& Hu, 1981); however, additional processes are involved in multi-digit magnitude processing (Huber, Nuerk, Willmes, \& Moeller, 2016; Nuerk, Moeller, Klein, Willmes, \& Fischer, 2011; Nuerk, Moeller, \& Willmes,2015). The distance effect has been suggested to signal an approximate representation of number magnitude (e.g., Dehaene, Dupoux, \& Mehler, 1990; Holloway \& Ansari, 2009). However, other research suggests that the distance effect originates from the monotonicity in connection weights between an input layer and a binary output layer (e.g., Verguts, Fias, $\&$ Stevens, 2005). Thus, differences in the distance effect just indicate differences in individuals' proficiency in comparing numbers, similar to reaction times and error rates, but do not represent magnitude processing. Accordingly, the previously reported influence of individual differences on reaction times and error rates should also hold for the distance effect.

The unit-decade compatibility effect indicates that the digits of multi-digit numbers are processed separately when two numbers are compared. For two-digit numbers, the comparison of tens and units can bias different responses. In the case of unit-decade compatible number pairs, comparing either tens or units leads to the same decision (e.g., 32 vs. 87 , with $3<8$ and $2<7$ ), whereas in the case of unit-decade incompatible number pairs, they bias different decisions (e.g., 38 vs. 91, with $3<9$, but $8>1$ ). NueNuerk, Weger, and Willmes (2001) observed that participants compare compatible number pairs faster and with higher accuracy than incompatible number pairs, supporting the notion that the magnitude of digits of multi-digit numbers is processed separately.

As a consequence, not only magnitude-related processes, but also processes related to conflict resolution of the incompatibility of the separate decisions are involved when comparing multi-digit numbers. Indeed, recent studies indicated that cognitive control processes influence the processing of multi-digit numbers (e.g., Huber, Mann, Nuerk, \& Moeller, 2014; Macizo \& Herrera, 2011, 2013; Moeller, Klein, \& Nuerk, 2013). The unit-decade compatibility effect depends on the proportion of within-decade filler items (e.g., 62 vs. $64)$ that are included in an item set: the larger the proportion of within-decade filler items to between-decade critical items, the larger the unit-decade compatibility effect. Macizo and Herrera (2011) explained this finding by suggesting that unit digits produce more cognitive conflict in conditions with more filler items, resulting in a larger unit-decade compatibility effect. Therefore, it seems that the influence of cognitive control on attentional focus is theoretically one of the most important issues in basic multi-digit number processing. The impact of cognitive control shows that even basic magnitude and place-value processing are not-or at least not fullyautomatic (see Kallai \& Tzelgov, 2012). Moreover, cognitive control may vary inter-individually. Therefore, we included the manipulation of cognitive control in our study by employing stimuli with and without fillers.

Accordingly, individual determinants influencing inhibitory control should also influence the unit-decade compatibility effect and the adaptation to filler items. In two-digit number comparison tasks with different decades, the unit magnitudes are irrelevant, which leads to cognitive conflict (Macizo, 2017). According to the conflict monitoring theory (Botvinick, Braver, Barch, Carter, \& Cohen, 2001) and the adaptation by binding theory (Verguts, \& Notebaert, 2009), the irrelevant information is discarded to select the correct number, particularly on incompatible trials, which generate longer response times. Macizo (2017) suggested that inhibitory control is the mechanism underlying the resolution of conflict in the unitdecade compatibility effect. Moreover, it has been shown that less efficient inhibitory control leads to a greater increase of the unit-decade compatibility effect due to the inclusion of filler items. Macizo and Herrera (2011; see also Huber et al., 2014, 2016) suggested that inhibitory control mechanisms are involved in the adaptation to different numbers of filler items. Thus, less efficient inhibitory control consequently results in a less efficient adaptation to a larger number of filler items. Note, however, that the size of the unit-decade compatibility effect might not only indicate the influence of cognitive control on multi-digit number processing, but might also indicate different processing strategies, for instance, due to differences in the reading and writing direction of numbers (e.g., Moeller et al., 2015).

While the cognitive mechanisms of symbolic magnitude processing and the relationship between symbolic magnitude processing and mathematical skills have been intensively studied, previous studies have paid less attention to individual differences influencing the processing of symbolic magnitude. A thorough understanding of individual differences influencing symbolic magnitude processing will be important to determine whether differences found between studies are indeed caused by differences in the methods of the experiment or by differences in the sample studied. For instance, different findings might be attributed to differences in the layout of the tasks, but might actually be caused by unequal proportions of male to female participants in the samples (e.g., Cahill, 2006). Therefore, in the present study, we aimed to investigate individual differences potentially influencing symbolic magnitude processing by means of an online study.

\section{Individual differences influencing multi-digit number processing}

\section{Age}

The magnitude comparison task is fundamentally a twochoice reaction task, and the typical slowing with age of 
response times in choice reaction tasks (e.g., Der \& Deary, 2006) was also found in symbolic number comparison (Norris, McGeown, Guerrini, \& Castronovo, 2015). In contrast, the accuracy of older adults seems to be higher than that of younger adults when comparing single-digit numbers (Norris et al., 2015). There is evidence that age also influences the distance effect. In the study of Norris et al. (2015), the distance effect for response times was more pronounced in older adults, whereas the distance effect for error rates was larger for younger adults. Additionally, research on cognitive aging suggests that inhibitory mechanisms are deficient in older adults (for a review, see Reuter-Lorenz \& Park, 2010). Hence, it might be argued that the unit-decade compatibility effect as well as the adaptation to filler items could depend on the age of participants. However, this has not yet been investigated.

\section{Gender}

In choice reaction tasks, there is evidence for faster reaction times by male participants compared to females (e.g., Der $\&$ Deary, 2006), and this also seems to be present in magnitude comparison tasks, at least when comparing single-digit numbers (Bull, Cleland, \& Mitchell, 2013). For two-digit numbers, Pletzer, Kronbichler, Nuerk, and Kerschbaum (2014) showed that gender differences additionally depend on the phase of women's menstrual cycles. Women during the luteal phase compared two-digit numbers faster than men. However, there was no significant difference for error rates in this study. Additionally, Bull et al. (2013) provided evidence for an influence of gender on the distance effect with a smaller effect for males than females. Furthermore, several studies provided evidence for less efficient inhibitory control associated with higher levels of estrogen (Colzato, Hertsig, van den Wildenberg, \& Hommel, 2010; Hatta \& Nagaya, 2009; Roberts, Newell, Simões-Franklin, \& Garavan, 2008), which suggests that the unit-decade compatibility effect should depend on gender. In line with this suggestion, Pletzer et al. (2014) observed that the unit-decade compatibility effect for response times was larger in women than in men, who did not show a significant compatibility effect. In contrast, with respect to error rates, they found a trend for a larger compatibility effect in men, compared to women in the follicular phase.

\section{Proficiency in mathematics and language}

Other individual differences capable of influencing reaction times and error rates in symbolic magnitude comparison tasks are more directly related to proficiency with numbers than to the general task layout. There is evidence that performance in two-digit number comparison is related to mathematics achievement. Castronovo and Göbel (2012) observed that faster response times in a multi-digit magnitude comparison task were related to greater mathematics achievement and proficiency in the native language. Moreover, Castronovo and Göbel (2012) found that smaller distance effects for accuracy in a multidigit magnitude comparison task were related to greater mathematics achievement. In contrast, spelling was not a significant predictor of the distance effect in the hierarchical regression analysis.

The influence of cognitive control on math achievement has been studied mostly in children (e.g., Bull \& Lee, 2014). Accordingly, we are not aware of any study in which the relationship between the unit-decade compatibility effect and mathematics achievement was investigated in adults. However, for children, there is evidence that the unit-decade compatibility effect is correlated with arithmetic performance (Moeller, Pixner, Zuber, Kaufmann, \& Nuerk, 2011). Children with a larger unit-decade compatibility effect in first grade showed a worse performance in an addition task 2 years later. With respect to language proficiency, Bahnmueller et al. (2016) argued that reading abilities, namely the ability to process many letters in parallel in the reading process, can heavily influence the processing of multi-digit numbers. Hence, proficiency in the native language might influence the size of the unit-decade compatibility effect.

\section{Education}

With respect to the effect of education on symbolic number processing, Zebian and Ansari (2012) observed that illiterate participants were slower in comparing single-digit numbers, while error rates did not differ significantly. Nys et al. (2013) replicated the finding of slower response times for two-digit number comparison (see also Wood, Nuerk, Freitas, Freitas, \& Willmes, 2006), but they additionally observed significantly higher error rates in a two-digit number comparison task for participants who never attended school, compared to participants who either attended school or received reading, writing and math education during alphabetization classes. Moreover, Zebian and Ansari (2012) reported a larger distance effect for response times in illiterate participants.

There is also evidence that education influences the unit-decade compatibility effect. Nys et al. (2013) provided evidence for a larger unit-decade compatibility effect for unschooled than for schooled participants. However, the observation of a larger unit-decade compatibility effect might only hold for this binary comparison, because Wood et al. (2006) did not find a significant correlation between the unit-decade compatibility effect and the duration of academic training (see also, Moeller et al., 2015). Thus, it is not yet clear how education influences the unit-decade compatibility effect. 


\section{Language}

Language influences multi-digit number processing (e.g., Bahnmueller, Huber, Nuerk, Göbel, \& Moeller, 2016; Bahnmueller, Moeller, Mann, \& Nuerk, 2015; Macizo, Herrera, Paolieri, \& Román, 2010; Macizo, Herrera, Román, \& Martín, 2011; Moeller, Shaki, Göbel, \& Nuerk,2015; Nuerk, Weger, \& Willmes, 2005; Van Rinsveld \& Schiltz, 2016; Van Rinsveld, Schiltz, Landerl, Brunner, \& Ugen, 2016). Languages can be divided into four categories depending on their reading/writing direction (left-to-right, e.g., English or German, and right-toleft, e.g., Hebrew or Arabic) and number word formation (non-inverted and inverted, e.g., 53 in English and 3-and50 in German; see Moeller et al., 2015). Although not statistically analysed by Moeller et al. (2015), the reported descriptive statistics suggest that mean response times differ between languages with left-to-right and right-toleft reading/writing direction. Participants with languages with a left-to-right reading/writing direction seem to be faster in comparing two-digit numbers than participants with languages with a right-to-left reading/writing direction. However, error rates seem to be comparable between the different language categories.

Moreover, Moeller et al. (2015) observed that the compatibility effects for response times differed between language categories. The unit-decade compatibility effect was significantly larger for languages with left-to-right reading direction and inverted number word formation (German) and for languages with right-to-left reading direction and non-inverted number formation (Hebrew) than for the other two categories. This suggests that the unit-decade compatibility effect is not only influenced by cognitive control, but also by properties of languages.

\section{Numeral system}

There is evidence that the numeral system influences the processing of the magnitude of symbolic numbers (GanorStern \& Tzelgov, 2008, 2010). Arabic digits can be compared faster than Indian digits, and error rates are smaller for Arabic digits than Indian digits. Furthermore, the distance effect depends on the numeral system (Ganor-Stern \& Tzelgov, 2008, 2010) with a smaller distance effect for Arabic digits than Indian digits. Ganor-Stern and Tzelgov (2010) also reported that the unit-decade compatibility effect was affected by the notation of the numeral system. It was larger when using a mixed notation of Arabic and Indian numerals compared to a pure Arabic or Indian numeral notation.

\section{Other individual differences potentially influencing multi-digit number processing}

In addition to these individual differences influencing number processing, there are several other individual differences that have not been studied in research on numerical cognition, but might influence symbolic magnitude comparison. In the present study, we were interested in the following individual differences: handedness, starting hand for counting, quality of sleep, alcohol consumption and time spent playing computer games. Their relationship to symbolic magnitude processing is less straightforward. However, some hypotheses can be derived from studies on related topics and by relating them to theoretical models of multi-digit number processing.

Handedness effects have been reported for other numerical effects such as the linguistic markedness of response codes (MARC) effect (Huber et al., 2015) or counting procedures in children (Patro, Nuerk, \& Cress, 2015). Regarding multi-digit number processing, Dehaene et al. (1990) reported no influence of handedness. However, their sample of left-handed participants was quite small. Hence, there is no conclusive evidence for either the presence or absence of an effect of handedness on symbolic number processing.

Counting habits can influence numerical processing like the spatial-numerical association of response codes (SNARC) effect (Fischer, 2008). However, we found only one study by Fabbri (2013) in which counting habits were investigated in combination with a symbolic number comparison task. Unfortunately, the study reported only results for the SNARC effect (which indicates faster left-hand responses to small numbers, but faster right-hand responses to large numbers, e.g., Dehaene, Bossini, \& Giraux, 1993), but neither for mean response times nor findings for the distance effect. Therefore, it is not clear whether counting habits (i.e., starting with the left or right to count) influence symbolic number processing.

Furthermore, we are not aware of studies that have investigated the influence of sleep quality, alcohol consumption or time spent playing computer games on symbolic number processing. Sleep deprivation results in slower response times and higher error rates (Killgore, 2010). In line with this, Steinborn et al. (2010) reported slower response times and higher error rates in a single-digit number comparison task depending on the circadian phase while participants stayed awake for $40 \mathrm{~h}$. In contrast, the distance effect was not affected by participants' staying awake. Moreover, inhibitory control is affected by sleep deprivation (Killgore, 2010) and hence, sleep quality might not only affect response times and error rates, but also the unit-decade compatibility effect. Likewise, drinking alcohol impairs performance in tasks requiring cognitive control (e.g., Easdon, Izenberg, Armilio, Yu, \& Alain, 2005), and frequent alcohol 
consumption might also affect the unit-decade compatibility effect. Finally, playing computer games reduces reaction times in speeded choice reaction tasks (Dye, Green, \& Bavelier, 2009a). Hence, playing computer games might also improve the speed of processing symbolic numbers in a symbolic magnitude comparison task. There is further evidence that video game players have a larger "spread of attention" than non-gamers, and hence are more susceptible to flankers (Dye, Green, \& Bavelier, 2009b). This suggests that the size of the unit-decade compatibility effect should also be greater for video game players than non-gamers.

\section{Present study}

Altogether, several individual differences may influence symbolic number processing. Some of them have been observed to influence number processing in small samples. However, in the context of the replicability crisis, an open question is whether an individual difference like gender really influences results, when one small study has reported gender differences among many others that have not. Therefore, in the present study, we have studied several individual differences at once, employing an online study. We were interested in whether the following individual differences influence symbolic number processing in adults: age, gender, proficiency in mathematics, proficiency in language, education, language, numeral system, handedness, starting hand for counting, quality of sleep, average alcohol consumption, and time spent playing computer games.

Online studies are especially suitable for investigating various individual differences at once, because they enable data collection from a large heterogeneous sample quickly (for summaries of advantages and disadvantages, see Birnbaum, 2004; Reips, 2002, 2012). Moreover, unlike typical studies skewed towards female psychology students, online studies more easily allow sampling from the general population.

Importantly, there is evidence that reaction time experiments can also be conducted online. In a recent review of the over 20 years of Internet-based experimenting Krantz and Reips (2017) conclude that "the web can be a method for conducting valid psychological studies". There are several online tools useful for building various experiments that have been previously conducted in labs. For instance, WEXTOR (http://wextor.org) is a Javascript-based tool to generate online studies with factorial designs including between-subject, within-subject, quasi-experimental factor, and mixed designs (Reips, \& Neuhaus, 2002). Crump, McDonnell, and Gureckis (2013) replicated several cognitive effects (e.g., the Stroop effect; Stroop, 1935) relying on Amazon's Mechanical Turk as a recruitment platform in an online experiment. They concluded that "even for extended experiments requiring problem solving and learning, and precise millisecond control for response collection and stimulus presentation, the data seem mostly in line with laboratory results so long as the experiment methods were solid". However, reflecting earlier experiences with Internet-based experimenting (Birnbaum, 2004; Reips, 2002), Crump et al. (2013) also noted some problems with online experiments, namely that computer systems vary widely between participants, which might influence the error in measuring reaction times, the precision of the timing of the display, and overall control of the environment. Moreover, data quality has to be ensured by the inclusion and exclusion criteria for participants (Reips, 2007). Still, the advantages far outweigh these problems, especially in the case of the present study, where we aimed to investigate several individual differences in symbolic number processing. This objective would not have been possible in a regular experimental setting within a reasonable time frame.

\section{Materials and methods}

\section{Participants}

Our initial sample consisted of 1259 participants. These were recruited from different sources, including the internal mailing systems of different universities, our homepages, social media, Web Experiment List (http://wexlist. net; Reips \& Lengler, 2005), and Psychological Research on the Net (https://psych.hanover.edu/research/exponnet. html). In the first step, we conservatively removed second and subsequent data points from IP addresses who accessed the experiment several times ("multiple submissions", Birnbaum, 2004; Reips, 2002). This reduced our sample to 1169 participants. We only included the 618 datasets from participants who finished the experiment. The next steps involved (1) removing data from participants who indicated that they did not want their data to be analysed (from a seriousness check at the beginning of the study), reducing the sample to 600 participants, (2) including only participants indicating they were over 18 years of age, or who did not specify their age, resulting in 595 participants, (3) removing data from participants who used a Tablet, Smartphone, E-reader or who did not specify which device they used, reducing the sample to 586 participants, and (4) removing data from participants who indicated that their environment was "very noisy" or "extremely noisy" resulting in a final sample size of 566 participants.

Average reported age was 26.05 years $(S D=8.23$ years, ranging from 18 to 72 years). Our sample included 362 female and 204 male participants. 498 participants 
Table 1 Demographic questions and predictors of interest

\begin{tabular}{|c|c|}
\hline Predictor & Note \\
\hline \multicolumn{2}{|l|}{ Age } \\
\hline Gender & Male, female, or transgender \\
\hline Handedness & Right, left, or ambidextrous \\
\hline Education & $\begin{array}{l}\text { School without qualification, school with qualification/GCSEs, high school with qualification/A levels, college } \\
\text { qualification, Bachelors degree, Masters degree, or PhD }\end{array}$ \\
\hline Field of study & Art, Science, Humanities and Social Science, Medicine/Veterinary/Dentistry, or other \\
\hline Latest grade in math & A scale of $0-10$ (from very poor to very good) \\
\hline Latest grade in language & A scale of $0-10$ (from very poor to very good) \\
\hline Numeral system & Arabic, Eastern Arabic or Indian, Chinese, or other \\
\hline Percentage of numeral system & $\begin{array}{l}\text { Depending on whether more than one numeral system was used, how often (in percent) a particular system was } \\
\text { used (only in case a specific numeral system was used more than } 5 \% \text { of the time) }\end{array}$ \\
\hline Starting hand for counting & Right or left \\
\hline Learning disabilities & Dyslexia, dysgraphia, dyscalculia, ADHD, or other \\
\hline Psychiatric illnesses & Only in case a participant suffered from one \\
\hline \multicolumn{2}{|l|}{ Nationality } \\
\hline \multicolumn{2}{|l|}{ Native language } \\
\hline Percentage of other languages & $\begin{array}{l}\text { Depending on whether a particular participant was multilingual, the amount of time (in percent) she/he spoke in } \\
\text { each language in the last } 3 \text { years (only more than } 5 \% \text { of the time) }\end{array}$ \\
\hline Sleep quality & A scale of $0-10$ (from very bad to very good) \\
\hline Alcohol consumption & Never, less than once a month, once a month, 2-3 times a month, once a week, 2-3 times a week, or daily \\
\hline Computer games & Never, less than once a month, once a month, 2-3 times a month, once a week, $2-3$ times a week, or daily \\
\hline Device used & PC, laptop, netbook, Tablet, Smartphone, E-reader, or other \\
\hline
\end{tabular}

Following Moeller et al. (2015), we did not include some other variables such as socio-economic status (SES) because they did not influence compatibility effect. However, they might influence cognitive controls and need to be taken into account for future studies

reported to be right-handed, 54 left-handed, 13 ambidextrous, and 1 participant did not specify her/his handedness. Participants were informed that ten randomly chosen participants would receive an Amazon voucher for participating in the experiment. All experimental procedures were approved by the local ethics committee of the Leibniz-Institut für Wissensmedien.

\section{Stimuli}

Participants had to compare two-digit numbers in two different conditions. In the first as well as the second condition, participants had to compare 60 compatible (e.g., 32 vs. 87 , with $3<8$ and $2<7$ ) and 60 incompatible (e.g., 38 vs. 91 , with $3<9$, but $8>1$ ) two-digit number pairs. In the second condition, we additionally included 120 filler items with the same tens (e.g., 62 vs. 64). In half of the compatible and incompatible two-digit number pairs, the absolute difference between tens (i.e., decade distance) was small (1-3); in the remaining half, it was large (4-7). We included only two-digit number pairs with large unit distances (4-8), which were shown to elicit a larger unit-decade compatibility effect than number pairs with small unit distances (Nuerk et al., 2001). This was for several reasons: first, we wanted to manipulate only the decade distance because it indexes the most prominent numerical representation, the magnitude representation. Second, individual factors might affect cognitive control and attentional focus in magnitude comparison, namely the decade distance. Third, while the effects of unit distance have been replicated several times, they are usually weak. Therefore, if there is little variance to be explained, there is little chance that covariance (i.e., individual predictors) explains it. Fourth, we intended to keep the experiment short because an online study should not be too long, otherwise participants may not complete the study (see Reips, 2002). Two-digit numbers ranged from 21 to 98.

Compatible and incompatible number pairs were a subset of the items used in the study of Ratinckx, Nuerk, van Dijck, and Willmes (2006). Thus, they were matched according to overall distance (compatible $M=34.68$ and incompatible $M=34.57$ ) and unit distance (compatible $M=5.18$ and incompatible $M=5.27$ ), but not decade distance (compatible $M=2.95$ and incompatible $M=3.98$ ). Note that it is impossible to match compatible and incompatible number pairs according to all three different distances.

\section{Design and procedure}

The online experiment was implemented using Qualtrics software (Qualtrics, Provo, UT). On the first page of the 
experiment, participants were instructed about the experiment and their informed consent was obtained. Participants were also given the opportunity to look at the experiment without their data being analysed. Finally, they had to indicate whether the device they used in completing the experiment had arrow keys or not. On the second page, we asked several questions regarding demographic data of the participants and our predictors of interest (cf. Table 1).

In the process of completing this questionnaire, participants either used their keyboard (e.g., to enter their age or nationality), selected one of the options via a drop-down list (e.g., the three options for gender), or moved a slider in the range of 0-10 (e.g., to rate their latest grades in mathematics). After completing the questionnaire, participants were instructed that in the following experiment, they should indicate the larger of two numbers by pressing either the up arrow key for the top number or the down arrow key for the bottom number. Moreover, they should use the middle finger of the dominant hand to press the up arrow key and the index finger of the dominant hand to press the down arrow key ${ }^{1}$. Then, they were given 12 practice trials to get familiar with the task setting. The experiment started with the first condition, followed by a break, after which participants completed the second condition. In both conditions, two-digit number pairs were presented in a pseudo-randomized order, namely using a maximum of three consecutive pairs from the same condition. This randomization was consistent for all participants. The pairs were presented vertically and jittered (the unit of the upper number was above the decade of lower number, or vice versa) on the screen.

After the experiment, we asked the participants about

- their approximate distance to the computer screen in centimeters,

- how noisy the environment was during the experiment (silent, very quiet, fairly quiet, fairly noisy, very noisy, or extremely noisy),

- the arrangement of the arrow keys on the keyboard,

- technical difficulties during the experiment,

- whether they would use the data, if they were the experimenter (yes, not all of them, or no), and

- whether they were interested in participating in a lottery for ten 20-Euro Amazon vouchers.

\section{Analysis}

First, we excluded data from 105 participants who used the mouse instead of the arrow keys to select the larger numbers in more than $5 \%$ of all trials. Then, we removed 9 additional

\footnotetext{
${ }^{1}$ Participants without arrow keys were excluded from data analysis.
}

participants who committed more than $25 \%$ errors in a given experiment, because the accuracy of participants in comparing two-digit number is usually larger than $95 \%$ (e.g., Nuerk et al., 2001). Thus, the final sample included 452 participants.

We first applied a gross trimming procedure to remove very fast response times ( $<150 \mathrm{~ms}$; e.g., Whelan, 2010) and very slow response times $(>3,000 \mathrm{~ms})$, resulting in a loss of $1.3 \%$ of the data ${ }^{2}$. We also excluded erroneous responses, removing an additional $2.2 \%$ of the data. As is typical for response time data (e.g., Ratcliff, 1993), the distribution of response times was highly rightward skewed (skewness $=2.21$ ). Hence, we applied a log transformation to response times $(\log \mathrm{RT})$ to approach normality. Afterwards, we applied a model-based outlier analysis (e.g., Baayen \& Milin, 2010) by trimming data points with z-normalized residuals larger than 3 , resulting in a loss of an additional $1.6 \%$ of the data. The model used in this process was a linear mixed model (LME) including the following fixed effects: condition (without and with fillers), compatibility (compatible and incompatible), and decade distance (small and large), as well as their higher level interactions. All fixed effects were effect-coded prior to data analysis. Moreover, as recommended by Barr, Levy, Scheepers, and Tily (2013), we used the maximum random effects structure for the random effects for participants. Additionally, we included a random intercept for items. The dependent variable of the LME was $\operatorname{logRT}$. LMEs were run using the statistics software R and the $\mathrm{R}$ package lme4 (Bates, Maechler, Bolker, \& Walker, 2015). To obtain $p$ values for fixed effects, we used the Satterthwaite approximation for degrees of freedom available via the $\mathrm{R}$ package ImerTest (Kuznetsova, Brockhoff, \& Christensen, 2016). The same LME was then used to test the significance of fixed effects.

For analyzing error rates, we ran a generalized linear mixed model (GLME) with binomial error distribution and logit as link function (Jaeger, 2008). In the GLME we included the same fixed effects as in the LME: condition (without and with fillers), compatibility (compatible and incompatible), and decade distance (small and large) as well as their higher level interactions. Moreover, we included random intercepts for participants as well as for items, and random slopes for condition, compatibility, decade distance, and the interaction between condition and compatibility. The $p$ values for fixed effects were calculated using likelihood ratio tests via the R package afex (Singmann, Bolker, Westfall, \& Aust, 2016).

\footnotetext{
${ }^{2}$ A more liberal trimming of error rate $(<50 \%)$ and response time (0-5000 ms instead of 150-3000 ms) did not change the results in any substantial way. However, based on the literature and low control on participants, we preferred more conservative data trimming.
} 
For the analyses of predictors, we used the estimated random effects for the intercept, the compatibility effect, the distance effect, and the interaction between condition and compatibility (as a measure of the influence of cognitive control in two-digit number comparison) of the LME for $\log R T$ and the GLME for error rates. Then, we removed outliers based on the absolute deviation around the median (MAD) which is the most robust dispersion measure in the presence of outliers in univariate statistics according to Leys, Ley, Klein, Bernard, and Licata (2013). Moreover, we used the suggested default threshold of 2.5 MAD in the trimming procedure. Thereby, we excluded the following respective percentages of participant data sets for the dependent variables of intercept, the compatibility effect, the distance effect, and the interaction between condition and compatibility in response times: 4.6, 4.6, 4.4, and $2.7 \%$ and in error rates: $1.3,3.3,1.8$, and $2.0 \%$.

The influence of predictors on these random effects was investigated by running ANOVAs for each predictor separately, which were corrected for multiple testing relying on the false discovery rate (Benjamini \& Hochberg, 1995). Moreover, we used ggplot2 (Wickham, 2009) and cowplot (Wilke, 2016) for drawing figures.

\section{Results}

\section{Two-digit number comparison}

\section{Response times}

We replicated the finding of a significant decade distance effect in two-digit number comparison, $F(1$, $245.04)=187.47, p<0.001$. Participants compared twodigit number pairs with a large decade distance faster than number pairs with a small decade distance (large decade distance: $\operatorname{logRT}: M=6.65, \mathrm{SE}=0.01$, back-transformed RT: $M=771 \mathrm{~ms}$; small decade distance: $\operatorname{logRT}: M=6.76$, $\mathrm{SE}=0.01$, back-transformed RT: $M=859 \mathrm{~ms})$. Moreover, the unit-decade compatibility effect was significant, $F(1$, $239.52)=22.75, p<0.001$, indicating faster responses to compatible than incompatible two-digit number pairs (compatible: $\operatorname{logRT}: M=6.68, \mathrm{SE}=0.01$, back-transformed RT: $M=798 \mathrm{~ms}$; incompatible: $\operatorname{logRT}: M=6.72, \mathrm{SE}=0.01$, back-transformed RT: $M=829 \mathrm{~ms})$. Furthermore, there was a main effect of condition, $F(1,343.33)=55.11, p<0.001$, with faster responses for the condition without filler items than with filler items (without filler: $\operatorname{logRT}: M=6.67$, $\mathrm{SE}=0.01$, back-transformed RT: $M=788 \mathrm{~ms}$; with filler: $\operatorname{logRT}: M=6.73$, back-transformed RT: $M=840 \mathrm{~ms}$ ).
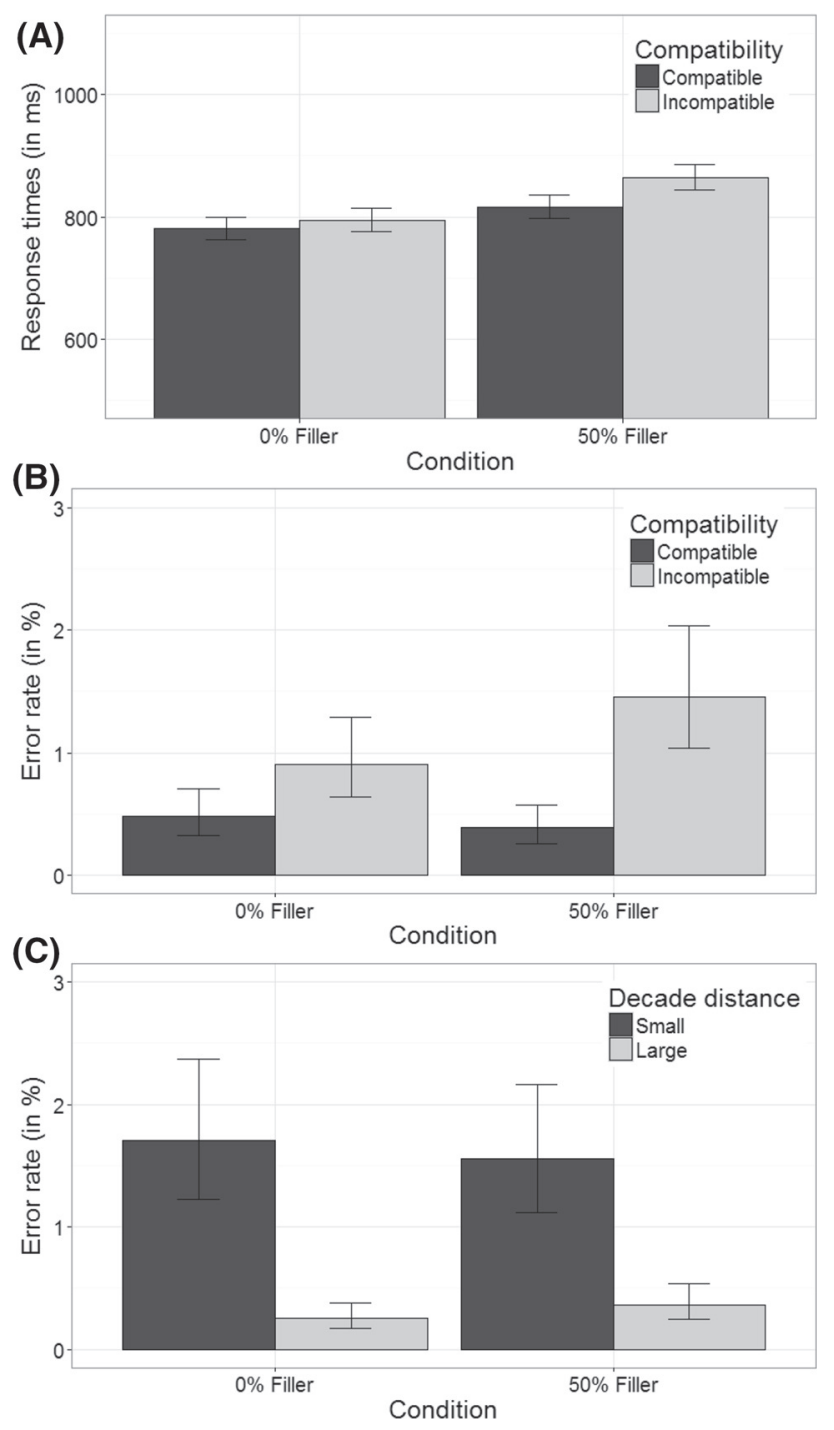

Fig. 1 Response times (a) and error rates (b) for compatible and incompatible two-digit number pairs, presented without and with filler items (a and b) and error rates for two-digit number pairs with small and large decade distances (c). Response times were calculated by back-transforming estimated $\operatorname{logRT}$, and error rates by back-transforming estimated log odds of fixed effects. Error bars indicate 95\% CIs

Finally, the interaction between compatibility and condition was significant, $F(1,233.06)=6.23, p=0.013$ (see Fig. 1a). The interaction indicated a larger unit-decade compatibility effect in the condition with filler items, $t(234.9)=1.63, p=0.105(\operatorname{logRT}: M=0.018, \mathrm{SE}=0.010$, back-transformed RT: $M=14 \mathrm{~ms}$ ) than without filler items, $t(238.1)=5.14, p<0.001(\operatorname{logRT}: M=0.057, \mathrm{SE}=0.010$, back-transformed RT: $M=48 \mathrm{~ms})$. Other interactions were not significant $(F<1.82, p>0.178)$. 


\section{Error rates}

Findings for error rates were very similar to the results for response times. We observed a significant decade distance effect, $\chi^{2}(1)=110.66, p<0.001$. Participants' error rates were lower when comparing two-digit number pairs with large decade distance than small decade distance (large decade distance: $\log$ odds: $M=-5.80, \mathrm{SE}=0.12$, backtransformed error rate: $M=0.3 \%$; small decade distance: $\log$ odds: $M=-4.10, \mathrm{SE}=0.10$, back-transformed error rate: $M=1.6 \%$ ). Moreover, we observed a significant unitdecade compatibility effect, $\chi^{2}(1)=42.24, p<0.001$, indicating a better performance when comparing compatible twodigit number pairs than incompatible pairs (compatible: log odds: $M=-5.44, \mathrm{SE}=0.11$, back-transformed error rate: $M=0.4 \%$; incompatible: $\log$ odds: $M=-4.46, \mathrm{SE}=0.10$, back-transformed error rate: $M=1.1 \%$ ). In contrast to response times, the effect of condition was not significant, $\chi^{2}(1)=0.46, p=0.496$.

Moreover, the interaction between condition and compatibility was significant, $\chi^{2}(1)=4.99, p=0.025$ (see Fig. 1b). The unit-decade compatibility effect was larger in the condition with filler items, $z=6.54, p<0.001$ (log odds: $M=1.33$, $\mathrm{SE}=0.20$, back-transformed error rates: $M=1.1 \%$ ) than in the condition without filler items, $z=3.19, p=0.003$ (log odds: $M=0.64, \mathrm{SE}=0.20$, back-transformed error rates: $M=0.4 \%$ ). Finally, we found a significant interaction between condition and decade distance, $\chi^{2}(1)=10.28$, $p=0.001$ (see Fig. 1c). The decade distance effect was larger in the condition without fillers, $z=9.59, p<0.001$ (log odds: $M=1.93, \mathrm{SE}=0.20$, back-transformed error rates: $M=1.5 \%)$, than in the condition with fillers, $z=7.36$, $p<0.001$ (log odds: $M=1.47, \mathrm{SE}=0.20$, back-transformed error rates: $M=1.2 \%$ ).

All other interactions were not significant, $\chi^{2}<0.34$, $p>0.558$.

\section{Predictors}

The average age of participants in our final sample was 26.00 years $(S D=8.08$ years, ranging from 18 to 70 years). The mean rating of grade in mathematics was $6.98(\mathrm{SD}=2.36)$ and in the native language was 7.92 $(\mathrm{SD}=1.79)$. Moreover, the mean rating of sleep quality was $6.50(\mathrm{SD}=1.82)$. The frequencies of the predictors are given in Fig. 2.

We coded language into four categories depending on their reading/writing direction (left-to-right, L-R or rightto-left, R-L) and number word formation (non-inverted or inverted, e.g., 53 or 3-and-50; see Moeller, Shaki, Göbel, \& Nuerk, 2015). The first category was non-inverted L-R (English, Chinese, Japanese, Korean, etc.) the second category was inverted L-R (German, including Austrian German, Swiss German, and Luxembourgish German), the third category was non-inverted R-L (Farsi, and Hebrew) and the fourth category was inverted R-L (Arabic).

Some of the categories were infrequent (i.e., frequency < 15). Of these groups, we excluded categories that could not be reclassified into another category. These were the category transgender $(n=0)$ from the factor gender, ambidextrous $(n=11)$ from the factor handedness, rightto-left and inverted $(n=5)$ from the factor language, and Chinese $(n=0)$ and other $(n=2)$ from the factor numeral system.

We combined the categories "2-3 times a week" and "daily" from the factor alcohol into "more than once a week." Furthermore, we created the new category "high school and below", which included the categories "school with qualification/GCSE" and "high school with qualification/A levels" (note that our final sample included no participant in the category "school without qualification"). Finally, we put the category "art" into the category "other" from the factor field of study.

\section{Response times}

Next, we conducted ANOVAs for each predictor and for each of the four dependent variables of interest: average $\operatorname{logRT}$, decade distance effect, unit-decade compatibility effect, and interaction between compatibility and condition. Results of the ANOVAs for logRT are given in Table 2. After correcting for multiple testing, we found that six predictors remained significant.

The effect of age indicated that $\log \mathrm{RT}$ increased with age, $M=0.003, \mathrm{SE}=0.001, \mathrm{RT}: M=2.55 \mathrm{~ms}$ (linear predictor of back-transformed RT in ms; see Fig. 3a). Moreover, the effect of grade in math indicated that $\log \mathrm{RT}$ decreased with proficiency in mathematics, $M=-0.009, \mathrm{SE}=0.003$, RT: $M=-6.84 \mathrm{~ms}$ (linear predictor of back-transformed RT in ms; see Fig. 3b).

The effect of gender was significant, with faster $\log \mathrm{RT}$ for male than female participants (see Table 3; Fig. 4a). Moreover, we observed that the effect of language was significant (see Table 3; Fig. 4b). The effect of language indicated similar $\log \mathrm{RT}$ for L-R languages, $t(419)=1.00, p=0.320$, but slower $\log \mathrm{RT}$ for non-inverted R-L languages: L-R noninverted vs. R-L non-inverted, $t(419)=4.57, p<0.001, \mathrm{~L}-\mathrm{R}$ inverted vs. R-L non-inverted, $t(419)=5.75, p<0.001$.

Additionally, there was a significant effect of alcohol consumption (see Table 3; Fig. 4c). Pairwise comparisons revealed that participants who never consumed alcohol had significantly larger logRT than all of the other groups, except for those who drank alcohol less than once a month, $t>2.95$, $p<0.014$; all other pairwise comparisons were not significant, $t<2.27, p>0.071$. 

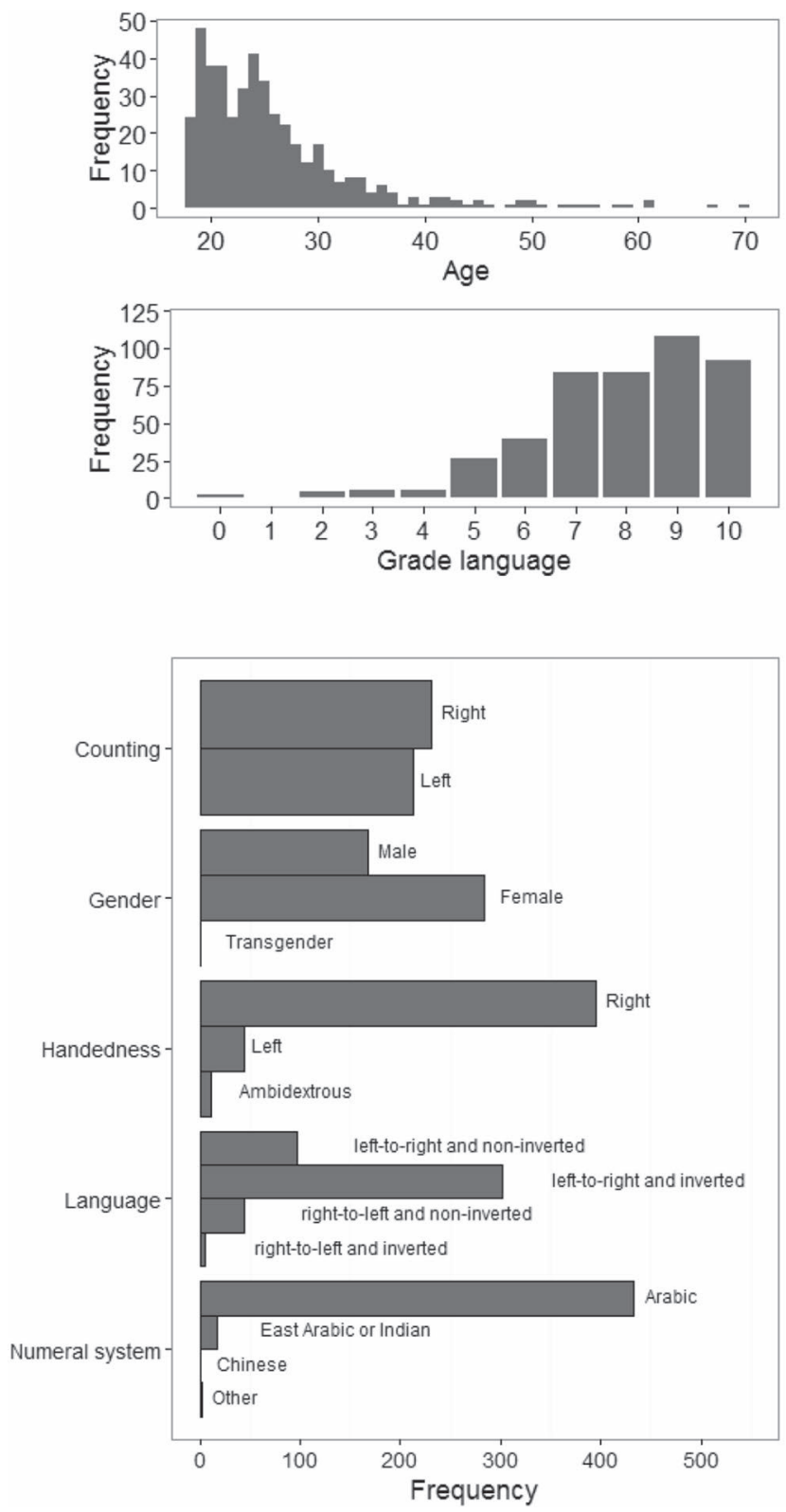

Fig. 2 Frequencies of the predictors investigated in the present study

Finally, there was an effect of reported computer gameplay on $\log$ RT (see Table 3; Fig. 4d). Pairwise comparisons revealed significant differences between never and 2-3 times a week, $t(424)=3.89, p=0.003$, and between never and daily, $t(424)=3.52, p=0.005$, whereas other comparisons were not significant, $t<2.63, p>0.062$. However, the means indicated a linear trend for faster $\log \mathrm{RT}$ the more often participants reported playing computer games. To test this assumption, we converted the factor into a continuous variable with $1=$ never, $2=$ less than once a month, and so on, and conducted a linear regression with this predictor variable, using $\log \mathrm{RT}$ as the dependent variable. The
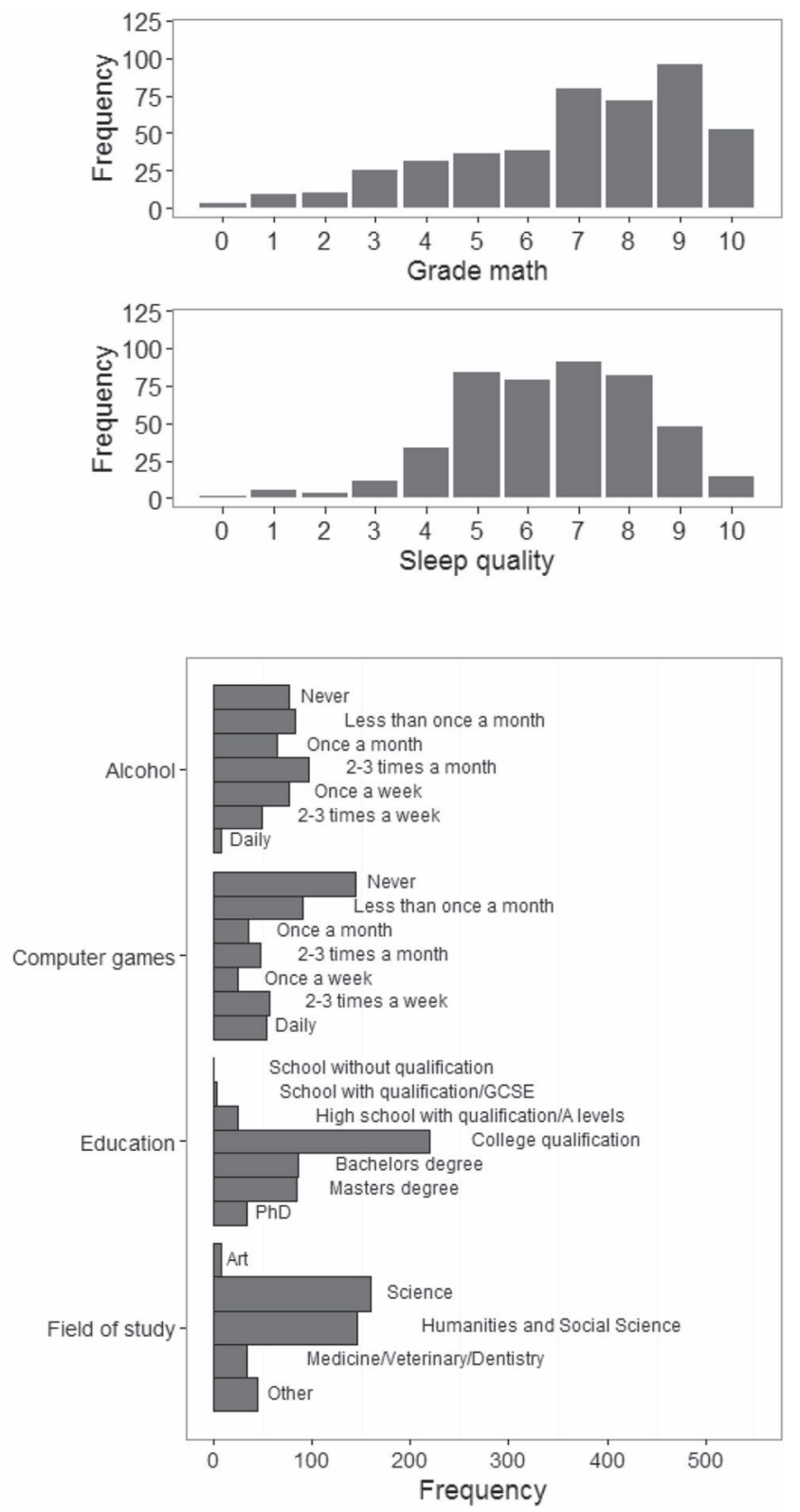

effect of reported frequency of playing computer games was highly significant, indicating that $\operatorname{logRT}$ decreased the more time was reportedly spent playing computer games, $t(429)=-4.70, p<0.001, M=-0.015, \mathrm{SE}=0.003, \mathrm{RT}$ : $M=-11.98 \mathrm{~ms}$ (linear predictor of back-transformed RT in $\mathrm{ms})$.

Results for the effect of predictors on the compatibility effect, the decade distance effect and on the interaction between compatibility and condition are given in Table 2 . We could replicate the influence of gender on the compatibility effect. The compatibility effect was larger for female participants than male participants (see Table 3). 
Table 2 ANOVA results for each predictor with $\operatorname{logRT}$ and effects as dependent variables

\begin{tabular}{|c|c|c|c|c|c|c|c|c|}
\hline Dependent variable & Predictor & $F$ & $d f 1$ & $d f 2$ & $R^{2}$ & Adj. $R^{2}$ & $p$ & $p_{\text {adj }}$ \\
\hline \multirow[t]{13}{*}{$\operatorname{LogRT}$} & Age & 12.28 & 1 & 429 & 0.028 & 0.026 & 0.001 & 0.007 \\
\hline & Grade math & 8.46 & 1 & 429 & 0.019 & 0.017 & 0.004 & 0.025 \\
\hline & Grade language & 0.02 & 1 & 428 & $<0.001$ & -0.002 & 0.894 & 0.935 \\
\hline & Sleep quality & 1.81 & 1 & 429 & 0.004 & 0.002 & 0.179 & 0.414 \\
\hline & Counting & 0.01 & 1 & 423 & $<0.001$ & -0.002 & 0.935 & 0.935 \\
\hline & Gender & 21.49 & 1 & 429 & 0.048 & 0.045 & $<0.001$ & $<0.001$ \\
\hline & Handedness & 0.35 & 1 & 417 & 0.001 & -0.002 & 0.555 & 0.848 \\
\hline & Language & 16.53 & 2 & 419 & 0.073 & 0.069 & $<0.001$ & $<0.001$ \\
\hline & Numeral system & 5.82 & 1 & 428 & 0.013 & 0.011 & 0.016 & 0.094 \\
\hline & Alcohol & 3.95 & 5 & 425 & 0.044 & 0.033 & 0.002 & 0.012 \\
\hline & Computer games & 3.92 & 6 & 424 & 0.053 & 0.039 & 0.001 & 0.007 \\
\hline & Education & 2.14 & 4 & 426 & 0.020 & 0.011 & 0.075 & 0.278 \\
\hline & Study & 1.08 & 3 & 371 & 0.009 & 0.001 & 0.358 & 0.665 \\
\hline \multirow[t]{13}{*}{ Comp. effect } & Age & 2.03 & 1 & 429 & 0.005 & 0.002 & 0.155 & 0.403 \\
\hline & Grade math & 1.90 & 1 & 429 & 0.004 & 0.002 & 0.169 & 0.414 \\
\hline & Grade language & 2.58 & 1 & 428 & 0.006 & 0.004 & 0.109 & 0.315 \\
\hline & Sleep quality & 0.23 & 1 & 429 & 0.001 & -0.002 & 0.629 & 0.911 \\
\hline & Counting & 1.56 & 1 & 423 & 0.004 & 0.001 & 0.213 & 0.461 \\
\hline & Gender & 16.28 & 1 & 429 & 0.037 & 0.034 & $<0.001$ & 0.001 \\
\hline & Handedness & 0.02 & 1 & 417 & $<0.001$ & -0.002 & 0.887 & 0.935 \\
\hline & Language & 1.71 & 2 & 419 & 0.008 & 0.003 & 0.183 & 0.414 \\
\hline & Numeral system & 2.63 & 1 & 428 & 0.006 & 0.004 & 0.106 & 0.315 \\
\hline & Alcohol & 1.17 & 5 & 425 & 0.014 & 0.002 & 0.324 & 0.624 \\
\hline & Computer games & 2.05 & 6 & 424 & 0.028 & 0.014 & 0.058 & 0.260 \\
\hline & Education & 0.48 & 4 & 426 & 0.005 & -0.005 & 0.747 & 0.935 \\
\hline & Study & 0.47 & 3 & 367 & 0.004 & -0.004 & 0.703 & 0.914 \\
\hline \multirow[t]{13}{*}{ Dec. distance effect } & Age & 2.98 & 1 & 430 & 0.007 & 0.005 & 0.085 & 0.295 \\
\hline & Grade math & 2.32 & 1 & 430 & 0.005 & 0.003 & 0.129 & 0.352 \\
\hline & Grade language & 0.53 & 1 & 429 & 0.001 & -0.001 & 0.466 & 0.782 \\
\hline & Sleep quality & 0.01 & 1 & 430 & $<0.001$ & -0.002 & 0.907 & 0.935 \\
\hline & Counting & 0.37 & 1 & 423 & 0.001 & -0.001 & 0.543 & 0.848 \\
\hline & Gender & 3.42 & 1 & 430 & 0.008 & 0.006 & 0.065 & 0.260 \\
\hline & Handedness & 3.54 & 1 & 418 & 0.008 & 0.006 & 0.060 & 0.260 \\
\hline & Language & 3.30 & 2 & 420 & 0.015 & 0.011 & 0.038 & 0.197 \\
\hline & Numeral system & 0.20 & 1 & 429 & $<0.001$ & -0.002 & 0.658 & 0.911 \\
\hline & Alcohol & 0.84 & 5 & 426 & 0.010 & -0.002 & 0.521 & 0.847 \\
\hline & Computer games & 1.32 & 6 & 425 & 0.018 & 0.004 & 0.248 & 0.496 \\
\hline & Education & 0.57 & 4 & 427 & 0.005 & -0.004 & 0.683 & 0.911 \\
\hline & Study & 1.41 & 3 & 370 & 0.011 & 0.003 & 0.239 & 0.496 \\
\hline \multirow[t]{13}{*}{ Comp. $\times$ condition } & Age & 0.68 & 1 & 438 & 0.002 & -0.001 & 0.409 & 0.733 \\
\hline & Grade math & 0.54 & 1 & 438 & 0.001 & -0.001 & 0.461 & 0.782 \\
\hline & Grade language & 0.01 & 1 & 437 & $<0.001$ & -0.002 & 0.930 & 0.935 \\
\hline & Sleep quality & 0.19 & 1 & 438 & $<0.001$ & -0.002 & 0.666 & 0.911 \\
\hline & Counting & 0.06 & 1 & 432 & $<0.001$ & -0.002 & 0.803 & 0.935 \\
\hline & Gender & 11.34 & 1 & 438 & 0.025 & 0.023 & 0.001 & 0.007 \\
\hline & Handedness & 0.03 & 1 & 426 & 0.000 & -0.002 & 0.872 & 0.935 \\
\hline & Language & 0.22 & 2 & 428 & 0.001 & -0.004 & 0.803 & 0.935 \\
\hline & Numeral system & 0.19 & 1 & 436 & $<0.001$ & -0.002 & 0.660 & 0.911 \\
\hline & Alcohol & 0.47 & 5 & 434 & 0.005 & -0.006 & 0.796 & 0.935 \\
\hline & Computer games & 1.83 & 6 & 433 & 0.025 & 0.011 & 0.092 & 0.298 \\
\hline & Education & 0.31 & 4 & 435 & 0.003 & -0.006 & 0.872 & 0.935 \\
\hline & Study & 0.20 & 3 & 376 & 0.002 & -0.006 & 0.895 & 0.935 \\
\hline
\end{tabular}

Comp. effect unit-decade compatibility effect, Dec. distance effect decade distance effect, and Comp. $\times$ condition interaction between compatibility and condition. $p_{\text {adj }}$ are $p$ values adjusted for multiple testing using the family-wise error rate (Benjamini \& Hochberg, 1995). The $p$ values of significant predictors are written in bold font 

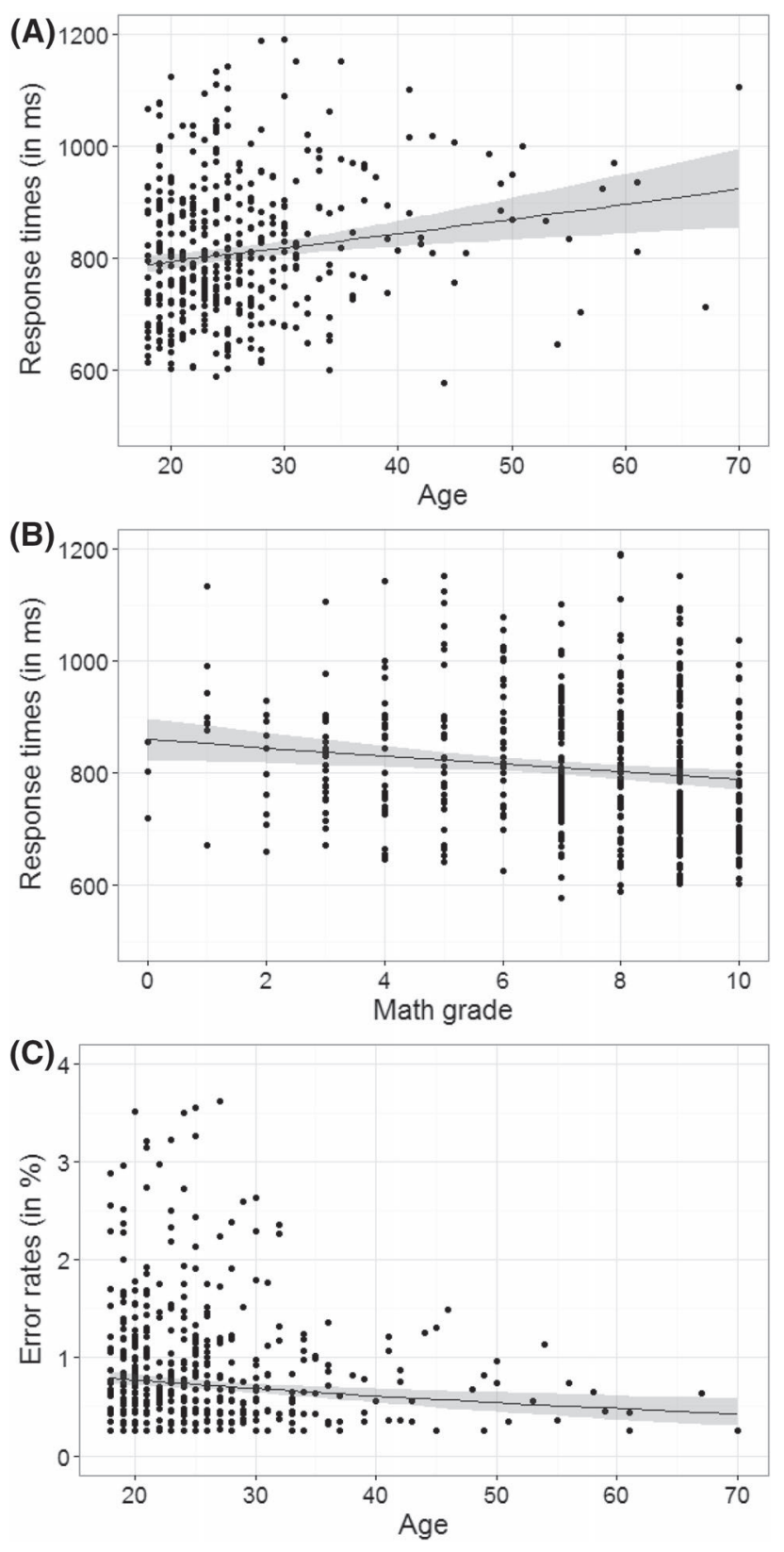

Fig. 3 Relationship between a response times and reported age, b response times and reported math grade, and c error rates and reported age. Response times were calculated by back-transforming $\operatorname{logRT}$, and error rates by back-transforming log odds. Shaded areas indicate $95 \%$ CIs

Finally, we also observed a significant effect of gender on the interaction between compatibility and condition. The compatibility effect increased more due to the inclusion of filler items for female participants than for male participants (see Table 3).

\section{Error rates}

Again, we ran an ANOVA for each predictor and for each of the four dependent variables of interest: average log odds, decade distance effect, unit-decade compatibility effect, and interaction between compatibility and condition. As can be seen in Table 4, we found only significant effects of reported age on the dependent variables.

Participants' error rates depended on their reported age. Error rates in comparing two-digit numbers decreased with reported age, $M=-0.012, \mathrm{SE}=0.004$, ER: $M=0.011 \%$ (linear predictor of back-transformed error rates; see Fig. 3c). The significant effect of reported age on the decade distance effect indicated that the effect decreased with age, $M=-0.003, \mathrm{SE}=0.001, \mathrm{ER}: M=-0.016 \%$ (linear predictor of back-transformed error rates). Finally, for the interaction between condition and compatibility, the effect of reported age was also significant. The effect of including filler items decreased with reported age, $M=-0.006, \mathrm{SE}=0.002$, ER: $M=-0.015 \%$ (linear predictor of back-transformed error rates).

\section{Discussion}

In the present study, we investigated several individual differences potentially influencing symbolic number processing. To do so, we ran an online experiment in which participants answered several questions regarding participant demographics and individual differences. Afterwards, they completed a two-digit number comparison task under two different conditions. Our results revealed that the effects found in a highly controlled experimental environment could be replicated on a personal computer or laptop in an uncontrolled environment, confirming once more the recent review of over 20 years of Internet-based experimenting (Krantz \& Reips, 2017). We found reliable distance and unit-decade compatibility effects in response times as well as in error rates (see also Nuerk et al., 2001). Moreover, we were able to replicate the adaptation to different numbers of filler items. As previously found (Huber et al., 2014; Macizo and Herrera, 2011), the unit-decade compatibility effect was more pronounced in the condition with $50 \%$ filler items. Thus, we can confirm the conclusion of Crump et al. (2013) that even experiments that require precise millisecond control for response collection and stimulus presentation can be implemented online. However, the compatibility effect in the condition without filler items (14 ms) was smaller than compatibility effects found previously (e.g., $31 \mathrm{~ms}$, Nuerk et al., 2001), while the compatibility effect found in the condition with filler items $(48 \mathrm{~ms}$ ) was comparable to the effect found by Huber et al. (2014) (46 ms). Compatibility effects found for error rates were smaller in the present Internet-based 
Table 3 Means (in $\log \mathrm{ms}$ ), standard errors (SE) and backtransformed RT (in ms) of significant predictor variables

\begin{tabular}{|c|c|c|c|c|c|}
\hline Dependent variable & Predictor & Level & $\operatorname{LogRT} M$ & LogRT SE & RT \\
\hline \multirow[t]{18}{*}{$\log \mathrm{RT}$} & \multirow[t]{2}{*}{ Gender } & Female & 6.72 & 0.01 & 829 \\
\hline & & Male & 6.65 & 0.01 & 775 \\
\hline & \multirow[t]{3}{*}{ Language } & L-R non-inverted & 6.69 & 0.01 & 808 \\
\hline & & $\mathrm{L}-\mathrm{R}$ inverted & 6.68 & 0.01 & 795 \\
\hline & & $\mathrm{R}-\mathrm{L}$ non-inverted & 6.82 & 0.02 & 916 \\
\hline & \multirow[t]{6}{*}{ Alcohol } & Never & 6.75 & 0.02 & 856 \\
\hline & & Less than once a month & 6.72 & 0.02 & 827 \\
\hline & & Once a month & 6.67 & 0.02 & 791 \\
\hline & & $2-3$ times a month & 6.69 & 0.02 & 801 \\
\hline & & Once a week & 6.66 & 0.02 & 784 \\
\hline & & More than once a week & 6.67 & 0.02 & 789 \\
\hline & \multirow[t]{7}{*}{ Computer games } & Never & 6.73 & 0.01 & 839 \\
\hline & & Less than once a month & 6.71 & 0.02 & 817 \\
\hline & & Once a month & 6.69 & 0.02 & 804 \\
\hline & & $2-3$ times a month & 6.71 & 0.02 & 817 \\
\hline & & Once a week & 6.66 & 0.03 & 783 \\
\hline & & 2-3 times a week & 6.65 & 0.02 & 772 \\
\hline & & Daily & 6.64 & 0.02 & 765 \\
\hline \multirow[t]{2}{*}{ Comp. effect } & \multirow[t]{2}{*}{ Gender } & Female & 0.033 & 0.0010 & 26 \\
\hline & & Male & 0.038 & 0.0008 & 32 \\
\hline \multirow[t]{2}{*}{ Comp. $\times$ condition } & \multirow[t]{2}{*}{ Gender } & Female & 0.040 & 0.0005 & 35 \\
\hline & & Male & 0.037 & 0.0007 & 31 \\
\hline
\end{tabular}

Comp. effect unit-decade compatibility effect, Dec. distance effect decade distance effect, and Comp. $\times$ condition interaction between compatibility and condition experiment than compatibility effects found in lab experimental settings (condition without fillers: $1.21 \%$ in Nuerk et al., 2001, vs. $0.4 \%$ in the present study; condition with fillers: $2.6 \%$ in Huber et al., 2014, vs. $1.1 \%$ in the present study). Nonetheless, we attribute such differences in the compatibility effects to differences in the samples employed; they do not necessarily indicate differences between lab and online experiments.

We also observed an interaction that was not previously reported for two-digit number comparison. For error rates, the decade distance effect depended on the proportion of filler items: it was larger in the condition without filler items. This supports the conclusion that cognitive control also influences the symbolic distance effect, at least in multidigit numbers (Huber, Moeller, Nuerk, \& Willmes, 2013; Moeller et al., 2013).

Our study revealed that language with an effect size of $R^{2}=0.073$, indicating a medium effect size (Cohen, 1988), had the largest impact on one of our dependent variables, i.e., response times. Thus, we replicated the finding that language influences response times (Moeller et al., 2015). As in the study by Moeller et al. (2015), we observed that participants with languages with left-to-right reading/writing direction were faster in comparing two-digit numbers than participants with languages with right-to-left reading/ writing direction. However, we did not find a significant difference between languages with non-inverted and inverted number word formation. Hence, participants benefit from a consistent writing direction for words and numbers when comparing two-digit numbers, but number word formation seems to be less important. We did not replicate the observation of the modulation of the unit-decade compatibility effect by language, which was found by several labs and in several samples (e.g., Bahnmueller et al., 2016, 2015; Ganor-Stern \& Tzelgov, 2008, 2010; Macizo et al., 2010, 2011; Moeller et al., 2015; Nuerk et al., 2005; Pixner, Moeller, Hermanova, Nuerk, \& Kaufmann, 2011; Van Rinsveld \& Schiltz, 2016; Van Rinsveld et al., 2016). However, it is known from other studies in numerical cognition that the influence of language on numerical cognition is highly dependent on pre-experimental conditions (Cipora, Patro, \& Nuerk, 2016; Fischer and Shaki, 2014). This seems to hold even for bilinguals (Prior, Katz, Mahajna, \& Rubinsten, 2015; Van Rinsveld \& Schiltz, 2016; Van Rinsveld et al., 2016). A possible weakness of the Internet-based study is that we cannot fully control the language encountered prior to our study. For instance, it is conceivable that many participants were not reading in their native language immediately before the experiment, but instead visited English websites. Previous studies with bilinguals indicate that their 
Fig. 4 Response times of factor levels for the predictors a reported gender, $\mathbf{b}$ reported language, $\mathbf{c}$ reported alcohol consumption and $\mathbf{d}$ reported time spent playing computer games. Response times were calculated by back-transforming $\log$ RT. Error bars indicate $95 \%$ CIs
(A)

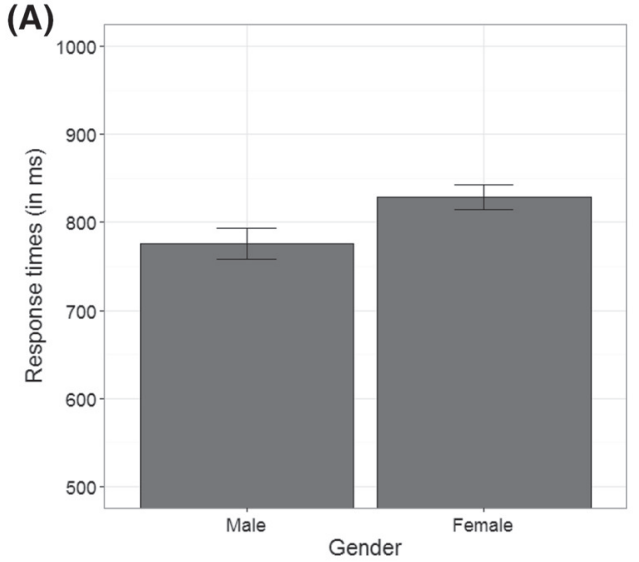

(B)
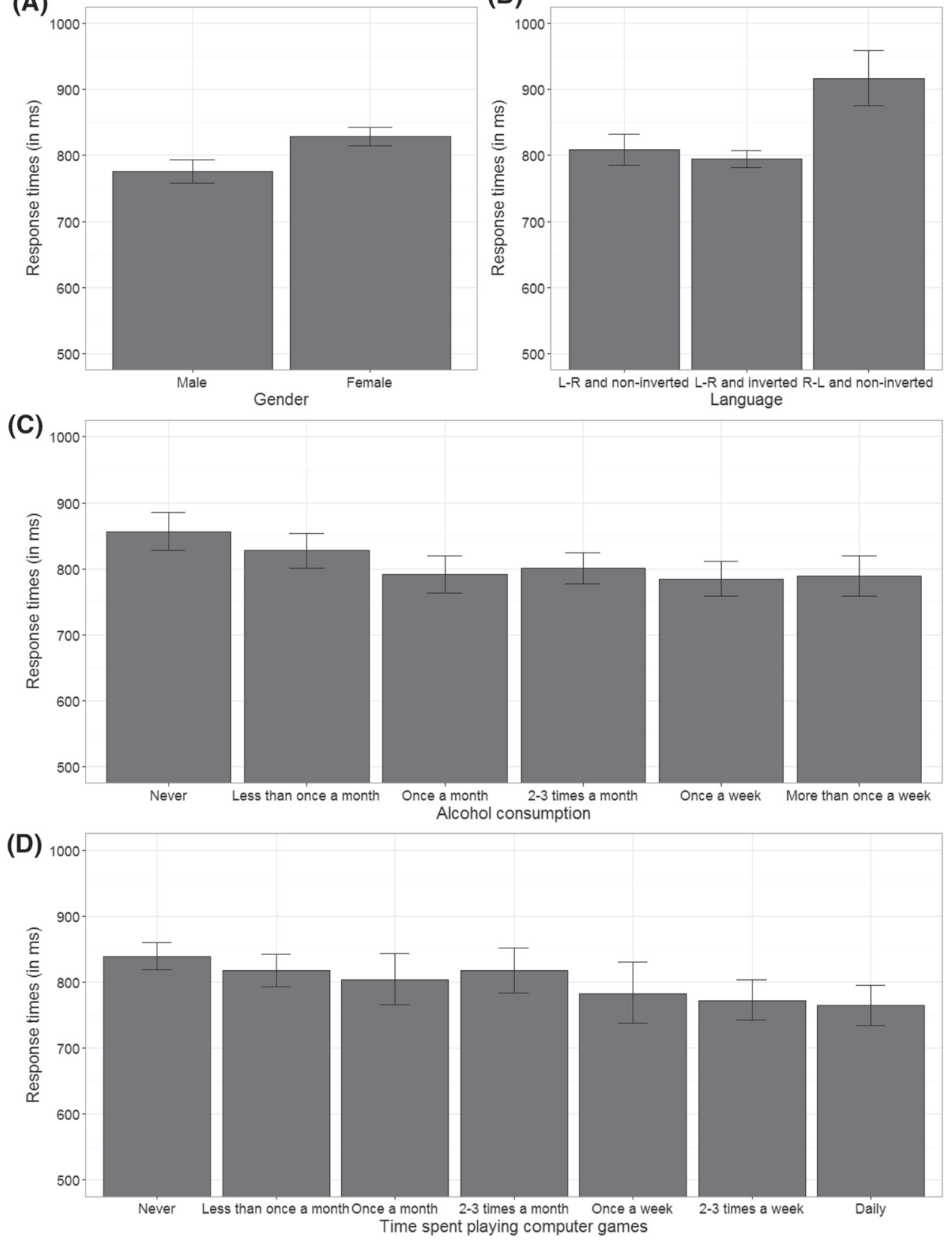

number processing would be then more similar to English (as a non-inverted LR language) than to their own native language. This holds at least when the manipulation is part of the experiment. Our data could be reconciled with previous language modulations of the compatibility effect such that language might exert an influence on place-value integration even when it is presented pre-experimentally. This interpretation of course deserves systematic experimental investigation, in which pre-experimental language influences are thoroughly controlled. Regardless, our online study suggests that language influences seem to be restricted to controlled experimental setups, and thus, that the modulation

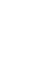


Table 4 ANOVA results for each predictor with estimated $\log$ odds for error rates and effects as dependent variables

\begin{tabular}{|c|c|c|c|c|c|c|c|c|}
\hline Dependent variable & Predictor & $F$ & $d f 1$ & $d f 2$ & $R^{2}$ & Adj. $R^{2}$ & $p$ & $p_{\text {adj }}$ \\
\hline \multirow[t]{13}{*}{ Log odds } & Age & 10.49 & 1 & 444 & 0.023 & 0.021 & 0.001 & 0.034 \\
\hline & Grade math & 0.58 & 1 & 444 & 0.001 & -0.001 & 0.445 & 0.811 \\
\hline & Grade language & 0.37 & 1 & 443 & 0.001 & -0.001 & 0.543 & 0.811 \\
\hline & Sleep quality & 0.13 & 1 & 444 & 0.000 & -0.002 & 0.720 & 0.857 \\
\hline & Counting & 0.62 & 1 & 436 & 0.001 & -0.001 & 0.432 & 0.811 \\
\hline & Gender & 0.93 & 1 & 444 & 0.002 & 0.000 & 0.335 & 0.811 \\
\hline & Handedness & 0.22 & 1 & 432 & 0.001 & -0.002 & 0.641 & 0.857 \\
\hline & Language & 0.45 & 2 & 434 & 0.002 & -0.003 & 0.640 & 0.857 \\
\hline & Numeral system & 0.20 & 1 & 442 & $<0.001$ & -0.002 & 0.653 & 0.857 \\
\hline & Alcohol & 1.07 & 5 & 440 & 0.012 & 0.001 & 0.376 & 0.811 \\
\hline & Computer games & 0.81 & 6 & 439 & 0.011 & -0.003 & 0.561 & 0.811 \\
\hline & Education & 1.15 & 4 & 441 & 0.010 & 0.001 & 0.330 & 0.811 \\
\hline & Study & 0.08 & 3 & 382 & 0.001 & -0.007 & 0.970 & 0.989 \\
\hline \multirow[t]{13}{*}{ Comp. effect } & Age & 3.21 & 1 & 435 & 0.007 & 0.005 & 0.074 & 0.641 \\
\hline & Grade math & 0.01 & 1 & 435 & $<0.001$ & -0.002 & 0.911 & 0.967 \\
\hline & Grade language & 2.67 & 1 & 434 & 0.006 & 0.004 & 0.103 & 0.662 \\
\hline & Sleep quality & 5.08 & 1 & 435 & 0.012 & 0.009 & 0.025 & 0.257 \\
\hline & Counting & 0.11 & 1 & 427 & $<0.001$ & -0.002 & 0.739 & 0.857 \\
\hline & Gender & 8.12 & 1 & 435 & 0.018 & 0.016 & 0.005 & 0.060 \\
\hline & Handedness & 1.26 & 1 & 424 & 0.003 & 0.001 & 0.263 & 0.811 \\
\hline & Language & 0.38 & 2 & 425 & 0.002 & -0.003 & 0.682 & 0.857 \\
\hline & Numeral system & 2.61 & 1 & 433 & 0.006 & 0.004 & 0.107 & 0.662 \\
\hline & Alcohol & 0.59 & 5 & 431 & 0.007 & -0.005 & 0.706 & 0.857 \\
\hline & Computer games & 1.57 & 6 & 430 & 0.021 & 0.008 & 0.155 & 0.662 \\
\hline & Education & 0.86 & 4 & 432 & 0.008 & -0.001 & 0.490 & 0.811 \\
\hline & Study & 1.08 & 3 & 373 & 0.009 & 0.001 & 0.357 & 0.811 \\
\hline \multirow[t]{13}{*}{ Dec. distance effect } & Age & 10.49 & 1 & 442 & 0.023 & 0.021 & 0.001 & 0.034 \\
\hline & Grade math & 1.82 & 1 & 442 & 0.004 & 0.002 & 0.178 & 0.662 \\
\hline & Grade language & 0.84 & 1 & 441 & 0.002 & 0.000 & 0.359 & 0.811 \\
\hline & Sleep quality & 0.07 & 1 & 442 & $<0.001$ & -0.002 & 0.793 & 0.896 \\
\hline & Counting & 0.35 & 1 & 434 & 0.001 & -0.001 & 0.554 & 0.811 \\
\hline & Gender & 0.71 & 1 & 442 & 0.002 & -0.001 & 0.401 & 0.811 \\
\hline & Handedness & 0.04 & 1 & 430 & $<0.001$ & -0.002 & 0.850 & 0.921 \\
\hline & Language & 1.48 & 2 & 432 & 0.007 & 0.002 & 0.230 & 0.797 \\
\hline & Numeral system & 0.85 & 1 & 440 & 0.002 & 0.000 & 0.356 & 0.811 \\
\hline & Alcohol & 1.53 & 5 & 438 & 0.017 & 0.006 & 0.178 & 0.662 \\
\hline & Computer games & 0.85 & 6 & 437 & 0.012 & -0.002 & 0.531 & 0.811 \\
\hline & Education & 1.07 & 4 & 439 & 0.010 & 0.001 & 0.372 & 0.811 \\
\hline & Study & 0.12 & 3 & 380 & 0.001 & -0.007 & 0.948 & 0.986 \\
\hline \multirow[t]{13}{*}{ Comp. $\times$ condition } & Age & 9.72 & 1 & 441 & 0.022 & 0.019 & 0.002 & 0.034 \\
\hline & Grade math & 0.44 & 1 & 441 & 0.001 & -0.001 & 0.509 & 0.811 \\
\hline & Grade language & 0.51 & 1 & 440 & 0.001 & -0.001 & 0.476 & 0.811 \\
\hline & Sleep quality & 2.05 & 1 & 441 & 0.005 & 0.002 & 0.153 & 0.662 \\
\hline & Counting & 0.12 & 1 & 433 & $<0.001$ & -0.002 & 0.734 & 0.857 \\
\hline & Gender & 0.74 & 1 & 441 & 0.002 & -0.001 & 0.389 & 0.811 \\
\hline & Handedness & $<0.01$ & 1 & 429 & $<0.001$ & -0.002 & 0.998 & 0.998 \\
\hline & Language & 0.60 & 2 & 431 & 0.003 & -0.002 & 0.551 & 0.811 \\
\hline & Numeral system & 1.84 & 1 & 439 & 0.004 & 0.002 & 0.175 & 0.662 \\
\hline & Alcohol & 0.83 & 5 & 437 & 0.009 & -0.002 & 0.532 & 0.811 \\
\hline & Computer games & 0.59 & 6 & 436 & 0.008 & -0.006 & 0.742 & 0.857 \\
\hline & Education & 1.63 & 4 & 438 & 0.015 & 0.006 & 0.165 & 0.662 \\
\hline & Study & 0.30 & 3 & 379 & 0.002 & -0.005 & 0.822 & 0.910 \\
\hline
\end{tabular}

Comp. effect unit-decade compatibility effect, Dec. distance effect decade distance effect, and Comp. $\times$ condition interaction between compatibility and condition. $p_{\text {adj }}$ are $p$ values adjusted for multiple testing using the family-wise error rate (Benjamini \& Hochberg, 1995). The $p$ values of significant predictors are written in bold font 
Table 5 Summary of significant results for each predictor with response times, error rates, and effects as dependent variables

\begin{tabular}{lll}
\hline Dependent variable & Predictor & Finding \\
\hline RT & Age & $\begin{array}{l}\text { Slower with increase of age } \\
\text { Foster with better math } \\
\text { grade } \\
\text { Faster in males }\end{array}$ \\
& Grade math & $\begin{array}{l}\text { Faster in left-to-right } \\
\text { Gender }\end{array}$ \\
& Language & Slower in never alcohol \\
& Alcohol & Faster in more gaming \\
& Computer games & Smaller in males \\
& Gender & - \\
Comp. effect & - & Smaller in males \\
Dec. distance effect & Gender & Smaller with increase of \\
Comp. $\times$ condition & age \\
ER & Age & - \\
Log odds & & Smaller with increase of \\
Comp. effect & - & age \\
Dec. distance effect & Age & Smaller with increase of \\
Comp. $\times$ Condition & Age & age \\
\hline
\end{tabular}

Comp. effectunit-decade compatibility effect, Dec. distance effect decade distance effect, and comp. $\times$ conditioninteraction between compatibility and condition

magnitude of symbolic numbers, but instead most likely indicates a general trend for faster reaction times in speeded choice reaction tasks for participants who play computer games (Dye et al., 2009a).

The third most influential individual difference reported was gender (cf. Table 5). It influenced not only overall reaction times $\left(R^{2}=0.048\right)$, but also the compatibility effect $\left(R^{2}=0.037\right)$, and the adaptation to filler items $\left(R^{2}=0.025\right)$. We replicated the observation of slower response times for female than for male participants (Bull et al., 2013). The difference between female and male participants could possibly be interpreted in terms of faster access to the magnitude of symbolic numbers for male participants. However, we could not replicate the modulation of the distance effect by gender, which this interpretation would suggest. Hence, our results do not provide evidence for the notion of a better spatial representation of symbolic numbers in male participants. This is in accordance with several recent studies, which question the assumption of a spatial representation of symbolic numbers (e.g., Dietrich, Huber, Moeller, \& Klein, 2015; Lyons \& Beilock, 2011; Van Opstal \& Verguts, 2011), but instead support the assumption that the distance effect is a result of the process of comparing symbolic numbers (Verguts et al., 2005).
Thus, our results might be interpreted in terms of a gender difference in choice reaction tasks instead (Deary \& Der, 2005). However, there is no conclusive evidence whether there is indeed a gender difference in choice reaction time tasks. Dykiert, Der, Starr, and Deary (2012) did not observe a significant gender difference in 4-choice reaction time task, in contrast to Deary and Der (2005). It might be the case that gender differences depend on the difficulty of choice reaction tasks, with gender differences being more prevalent in easier tasks (like the 2-choice reaction task of this study). Supporting this idea, gender differences were repeatedly found for simple reaction time tasks (Deary \& Der, 2005; Der \& Deary, 2006; Dykiert et al., 2012).

We also observed that gender had an influence on the unit-decade compatibility effect, replicating the findings of Pletzer et al. (2014) that showed a larger compatibility effect for women than for men after controlling for overall response times. However, we could not replicate the trend for a significant difference in the compatibility effects between men and women as measured by error rates (cf. Table 5). Nevertheless, the explanation of Pletzer and colleagues for different gender-based compatibility effects might also hold for our data. Several studies provide evidence for less efficient inhibitory control associated with higher levels of estrogen (Colzato et al., 2010; Hatta \& Nagaya, 2009; Roberts et al., 2008). We did not ask female participants about their menstrual cycle; however, on average, women in our study naturally had higher levels of estrogen than men, resulting in less efficient inhibitory control. This in turn reduced the ability to inhibit the incompatible unit digits and thereby increased the unit-decade compatibility effect (Macizo and Herrera, 2011; Huber et al., 2014).

The effect size of one of our more exploratory individual differences, i.e., alcohol consumption, with an effect size of $R^{2}=0.044$, was similar to the effect size of gender. Not consuming alcohol at all was associated with overall slower response times than consuming alcohol (cf. Table 5). An explanation might be that the effect of alcohol consumption is just an effect of language, as alcohol is prohibited for the majority of the citizens in Iran (with Farsi as the official language) as well as in most Arabic countries, and participants speaking Farsi (a language with right-to-left reading/writing direction) were slower when comparing two-digit numbers. Running a chi-squared test of independence supported the conclusion that language and alcohol consumption were confounded in our study, $\chi^{2}(10)=34.76, p<0.001$, and hence, we cannot disentangle effects of alcohol consumption from effects of language in the present study. Therefore, further studies are required to study the influence of alcohol consumption on symbolic number comparison in more detail.

Additionally, our study revealed that age influenced not only response times and error rates, but also several effects including the distance effect and the adaptation to filler items 
(cf. Table 5). However, effect sizes of significant effects of age were rather small $\left(R^{2}=0.022-0.028\right)$. We were able to replicate the findings of Norris et al. (2015), wherein older participants were slower to compare symbolic numbers, most likely due to a decline in processing speed (Salthouse, 1996), but in turn were more accurate in comparing numbers. Thus, they traded speed to gain accuracy. Additionally, our results suggest that symbolic number comparison abilities are preserved in aging. Interestingly, in contrast to nonsymbolic number comparison (Cappelletti, Didino, Stoianov, $\&$ Zorzi, 2014), we found no evidence that inhibitory processes involved in multi-digit number comparison decline with age; instead they seem to improve. Older participants could adapt better to a larger number of filler items, which was caused most probably by their overall higher accuracy.

Finally, the present study also supports the idea that symbolic magnitude comparison skills are related to math abilities (e.g., De Smedt et al., 2013; Schneider et al., 2016), but only to a small degree, as reported grades in mathematics explained only about $2 \%$ of the variance found in reaction times $\left(R^{2}=0.019\right)$. We observed that participants who compared two-digit numbers faster reported higher grades in mathematics (cf. Table 5). It may be argued that proficiency in symbolic number processing aids the acquisition of arithmetic skills and of math abilities in general. Moreover, our study supports the notion of De Smedt et al. (2013) that the relationship between overall reaction times and math abilities seems to be more robust than the correlation between the distance effect and math abilities, because we did not find a significant correlation between the distance effect and math abilities in the present study. This might be due to the small reliability of the symbolic distance effect (Maloney, Risko, Preston, Ansari, \& Fugelsang, 2010), which limits the size of correlations with the distance effect (see also Dietrich, Huber, \& Nuerk, 2015, for a discussion of the importance of considering reliability when investigating the relationship between number processing skills and math abilities).

In our results, some variables modulated performance in RT measures but not in error analyses (e.g., computer gaming) while the opposite was found in other variables (e.g., age). In memory retrieval tasks, response times index difficulty in memory retrieval processes, while error rates also index encoding processes. Interference and competition in memory occur at the retrieval stage of processing (e.g., Anderson, 1982). Because the unit-decade-compatibility effect is an interference effect, reaction times might be the preferred measure for capturing the unit-decade compatibility effect in the current study. Nevertheless, the fact that some variables (like age) affect the error rate suggests that these variables may modulate the encoding processes necessary for place-value integration. ${ }^{3}$

\section{Conclusions}

In the present study, we provided evidence that typical experiments employed in numerical cognition utilizing a keyboard as an input device can also be run online. Online experiments have the benefit that it is possible to collect data from a large heterogeneous sample quickly. This makes it possible to investigate whether effects found in highly controlled experimental settings with a homogeneous sample can be replicated in a heterogeneous sample, and in a more realistic setting. In the present study, we provided evidence that replication is possible for effects including the distance effect, the unit-decade compatibility effect and the effect of cognitive control on the adaptation to filler items, found in two-digit number comparison. Moreover, a large heterogeneous sample allows for the investigation of the impact of individual differences on numerical cognition. The findings of the present study suggest that several individual differences influence the performance in symbolic number comparison. Studying individual differences is very important for research in psychology, because such factors may confound results in between-participant designs. Moreover, individual differences need to be considered when comparing the results of different experiments. For numerical comparisons, we found that the most influential individual differences were participants' reported language, reported time spent playing computer games, and reported gender. Thus, individual differences which contribute to performance in choice reaction tasks also influence number comparison. However, weekly alcohol consumption, age and proficiency in mathematics might also cause differences between studies. Note that most of the investigated factors in the present study influence response times, and only gender influences the compatibility effect and an interaction between condition and compatibility. Moreover, age was the only factor that influenced the distance effect, the most important measure of magnitude processing in two-digit number comparison, in the error rate analysis. Altogether, we suggest taking these individual differences into account when comparing findings from different experiments or studies recruiting different samples. However, we acknowledge the limitations of our conclusions regarding domain-general and domain-specific factors mediating the observed effects; future research is needed to delineate these influences.

$\overline{3}$ We wish to thank an anonymous reviewer for pointing this out to us. 
Acknowledgements We would like to thank all participants. We thank colleagues and friends, who translated the experiment into different languages and helped to access people. Hans-Christoph Nuerk and Mojtaba Soltanlou are supported by the Science Campus Tuebingen, project 8.4. Mojtaba Soltanlou is also supported by the DFG grant (NU 265/3-1) to Hans-Christoph Nuerk. Hans-Christoph Nuerk is further supported by the LEAD Graduate School \& Research Network (GSC1028), a project of the Excellence Initiative of the German federal and state governments, and Stefan Huber is supported by the LeibnizCompetition Fund (SAW-2014-IWM-4) providing funding to Elise Klein. Finally, we thank Julianne Skinner for the language proofreading of the manuscript.

\section{Compliance with ethical standards}

Conflict of interest The authors declare that they have no conflict of interest.
Ethical approval All procedures performed in studies involving human participants were in accordance with the ethical standards of the institutional and/or national research committee and with the 1964 Helsinki declaration and its later amendments or comparable ethical standards.

Informed consent Informed consent was obtained from all individual participants included in the study.

\section{Appendix A: demographic information of drop-outs}

See Table 6 .
Table 6 The comparison between reported demographic information of included and drop-out participants

\begin{tabular}{|c|c|c|c|}
\hline Variable & $t$ OR $x^{2}(d f)$ & $p$ & Notice \\
\hline Age & $t(833)=-2.23$ & 0.03 & $\begin{array}{l}\text { Included: } M(\mathrm{SD})=26.00(8.08) \text {; range: } 18-70 \text { yo } \\
\text { Drop-out: } M(\mathrm{SD})=27.31(9.14) ; \text { range: } 15-66 \text { уо }\end{array}$ \\
\hline Gender & $x^{2}(4)=6$ & 0.20 & $\begin{array}{l}\text { Included: f: } 284, \mathrm{~m}: 168, \mathrm{t}: 0 \\
\text { Drop-out: f: } 246, \mathrm{~m}: 172, \mathrm{t}: 3\end{array}$ \\
\hline Language & $x^{2}(9)=12$ & 0.21 & $\begin{array}{l}\text { Included: a: } 97 \text {; b: } 302 ; \text { c: } 44 ; \text { d: } 5 \\
\text { Drop-out: a: } 89 \text {; b: } 272 ; \text { c: } 38 ; \text { d: } 11\end{array}$ \\
\hline Math proficiency & $t(872)=-0.13$ & 0.90 & $\begin{array}{l}\text { Included: } M(\mathrm{SD})=6.98(2.36) ; \text { range: } 0-10 \\
\text { Drop-out: } M(\mathrm{SD})=7.00(2.35) ; \text { range: } 0-10\end{array}$ \\
\hline Language proficiency & $t(852)=0.61$ & 0.54 & $\begin{array}{l}\text { Included: } M(\mathrm{SD})=7.92(1.79) ; \text { range: } 0-10 \\
\text { drop-out: } M(\mathrm{SD})=7.84(1.93) ; \text { range: } 0-10\end{array}$ \\
\hline Education & $x^{2}(36)=42$ & 0.23 & $\begin{array}{l}\text { Included: a: } 0 ; \text { b: } 3 \text {; c: } 25 ; \text { d: } 220 ; \text { e: } 86 ; \text { f: } 85 ; \text { g: } 33 \\
\text { Drop-out: a: } 8 ; \text { b: } 4 \text {; c: } 31 \text { d: } 164 \text {; e: } 71 ; \text { f: } 99 ; \text { g: } 44\end{array}$ \\
\hline Handedness & $x^{2}(4)=6$ & 0.20 & $\begin{array}{l}\text { Included: r: } 395,1: 45 \text {, a: } 11 \\
\text { Drop-out: } \mathrm{r}: 366,1: 43 \text {, a: } 13\end{array}$ \\
\hline Counting hand & $x^{2}(1)=2$ & 0.16 & $\begin{array}{l}\text { Included: } r: 231 ; 1: 213 \\
\text { Drop-out: r: } 245 ; 1: 176\end{array}$ \\
\hline Number system & $x^{2}(9)=12$ & 0.21 & $\begin{array}{l}\text { Included: a: } 432 ; \text { b: } 18 ; \text { c: } 0 ; \text { d: } 2 \\
\text { Drop-out: a: } 404 ; \text { b: } 19 ; \text { c: } 2 ; \text { d: } 3\end{array}$ \\
\hline Sleep quality & $t(849)=1.01$ & 0.31 & $\begin{array}{l}\text { Included: } M(\mathrm{SD})=6.50(1.82) ; \text { range: } 0-10 \\
\text { Drop-out: } M(\mathrm{SD})=6.37(1.98) ; \text { range: } 0-10\end{array}$ \\
\hline Alcohol consumption & $x^{2}(30)=35$ & 0.24 & $\begin{array}{l}\text { Included: a: } 76 ; \text { b: } 82 ; \text { c: } 65 ; \text { d: } 97 \text {; e: } 76 \text {; f: } 49 ; \text { g: } 7 \\
\text { Drop-out: a: } 50 ; \text { b: } 79 ; \text { c: } 47 \text { d: } 95 ; \text { e: } 81 ; \text { f: } 62 ; \text { g: } 8\end{array}$ \\
\hline Gaming & $x^{2}(36)=42$ & 0.23 & $\begin{array}{l}\text { Included: a: } 144 \text {; b: } 91 \text {; c: } 35 \text {; d: } 48 \text {; e: } 24 \text {; f: } 57 \text {; g: } 53 \\
\text { Drop-out: a: } 150 \text {; b: } 102 ; \text { c: } 31 \text {; d: } 25 \text {; e: } 30 \text {;: } 43 \text {; g: } 41\end{array}$ \\
\hline
\end{tabular}

Gender: $f$ female, $m$ male, $t$ transgender

Language: $a$ left-to-right reading $\&$ no-inversion; $b$ left-to-right reading $\&$ inversion; $c$ right-to-left reading \& no-inversion; $d$ right-to-left reading $\&$ inversion

Education: a school without qualification; bschool with qualification/GCSE; chigh school with qualification/A levels; $d$ College qualification; $e$ Bachelors degree; $f$ Masters degree; $g \mathrm{PhD}$

Handedness: $r$ right, $l$ left, $a$ ambidextrous

Counting hand: $r$ right, $l$ left

Number system: $a$ Arabic; $b$ Eastern Arabic; $c$ Chinese; $d$ other

Alcohol consumption: $a$ never; $b$ less than once a month; $c$ once a month; $d 2-3$ times a month; $e$ once a week; $f 2-3$ times a week; $g$ daily

Gaming: $a$ never; $b$ less than once a month; $c$ once a month; $d 2-3$ times a month; $e$ once a week; $f 2-3$ times a week; $g$ daily 


\section{References}

Anderson, J. R. (1982). Acquisition of cognitive skill. Psychological review, 89(4), 369.

Baayen, R. H., \& Milin, P. (2010). Analyzing reaction times. International Journal of Psychological Research, 3(2), 12-28.

Bahnmueller, J., Huber, S., Nuerk, H.-C., Göbel, S. M., \& Moeller, K. (2016). Processing multi-digit numbers: A translingual eye-tracking study. Psychological Research Psychologische Forschung, 80(3), 422-433. https://doi.org/10.1007/s00426-015-0729-y.

Bahnmueller, J., Moeller, K., Mann, A., \& Nuerk, H.-C. (2015). On the limits of language influences on numerical cognition - no inversion effects in three-digit number magnitude processing in adults. Frontiers in Psychology, 6, 1216. https://doi.org/10.3389/ fpsyg.2015.01216.

Barr, D. J., Levy, R., Scheepers, C., \& Tily, H. J. (2013). Random effects structure for confirmatory hypothesis testing: Keep it maximal. Journal of Memory and Language, 68(3), 255-278. https:// doi.org/10.1016/j.jml.2012.11.001.

Bates, D., Maechler, M., Bolker, B., \& Walker, S. (2015). Fitting linear mixed-effects models using lme4. Journal of Statistical Software, 67(1), 1-48. https://doi.org/10.18637/jss.v067.i01.

Benjamini, Y., \& Hochberg, Y. (1995). Controlling the false discovery rate: A practical and powerful approach to multiple testing. Journal of the Royal Statistical Society. Series B (Methodological), 57(1), 289-300. https://doi.org/10.2307/2346101.

Birnbaum, M. H. (2004). Human research and data collection via the internet. Annual Review of Psychology, 55(1), 803-832. https:// doi.org/10.1146/annurev.psych.55.090902.141601.

Botvinick, M. M., Braver, T. S., Barch, D. M., Carter, C. S., \& Cohen, J. D. (2001). Conflict monitoring and cognitive control. Psychological review, 108(3), 624. https://doi org/10.1037/0033-295X.108.3.624.

Bull, R., Cleland, A. A., \& Mitchell, T. (2013). Sex differences in the spatial representation of number. Journal of Experimental Psychology: General, 142(1), 181-192. https://doi.org/10.1037/ a0028387.

Bull, R., \& Lee, K. (2014). Executive functioning and mathematics achievement. Child Development Perspectives, 8(1), 36-41. https://doi.org/10.1111/cdep.12059.

Cahill, L. (2006). Why sex matters for neuroscience. Nature Reviews Neuroscience, 7(6), 477-484. https://doi.org/10.1038/nrn1909.

Cappelletti, M., Didino, D., Stoianov, I., \& Zorzi, M. (2014). Number skills are maintained in healthy ageing. Cognitive Psychology, 69, 25-45. https://doi.org/10.1016/j.cogpsych.2013.11.004.

Castronovo, J., \& Göbel, S. M. (2012). Impact of high mathematics education on the number sense. PLoS One, 7(4), e33832. https:// doi.org/10.1371/journal.pone.0033832.

Cipora, K., Patro, K., \& Nuerk, H.-C. (2016). Situated influences on spatial-numerical associations. In T. Hubbard (Ed.), Spatial Biases in Perception and Cognition. Cambridge: Cambridge University Press.

Cohen, J. (1988). Statistical Power Analysis for the Behavioral Sciences. New York: Routledge Academic.

Colzato, L. S., Hertsig, G., van den Wildenberg, W. P. M., \& Hommel, B. (2010). Estrogen modulates inhibitory control in healthy human females: Evidence from the stop-signal paradigm. Neuroscience, 167(3), 709-715. https://doi.org/10.1016/j. neuroscience.2010.02.029.

Crump, M. J. C., McDonnell, J. V., \& Gureckis, T. M. (2013). Evaluating amazon's mechanical turk as a tool for experimental behavioral research. PLoS One, 8(3), e57410. https://doi.org/10.1371/ journal.pone.0057410.
De Smedt, B., Noël, M.-P., Gilmore, C., \& Ansari, D. (2013). How do symbolic and non-symbolic numerical magnitude processing skills relate to individual differences in children's mathematical skills? A review of evidence from brain and behavior. Trends in Neuroscience and Education, 2(2), 48-55. https://doi. org/10.1016/j.tine.2013.06.001.

Deary, I. J., \& Der, G. (2005). Reaction time, age, and cognitive ability: Longitudinal findings from age 16 to 63 years in representative population samples. Aging, Neuropsychology, and Cognition, 12(2), 187-215. https://doi.org/10.1080/13825580590969235.

Dehaene, S., Bossini, S., \& Giraux, P. (1993). The mental representation of parity and number magnitude. Journal of Experimental Psychology: General, 122(3), 371-396. https://doi. org/10.1037/0096-3445.122.3.371

Dehaene, S., Dupoux, E., \& Mehler, J. (1990). Is numerical comparison digital? Analogical and symbolic effects in two-digit number comparison. Journal of Experimental Psychology: Human Perception and Performance, 16(3), 626-641.

Der, G., \& Deary, I. J. (2006). Age and sex differences in reaction time in adulthood: Results from the United Kingdom Health and Lifestyle Survey. Psychology and Aging, 21(1), 62-73. https://doi. org/10.1037/0882-7974.21.1.62.

Dietrich, J. F., Huber, S., Moeller, K., \& Klein, E. (2015). The influence of math anxiety on symbolic and non-symbolic magnitude processing. Frontiers in Psychology, 6:1621. https://doi.org/10.3389/ fpsyg.2015.01621.

Dietrich, J. F., Huber, S., \& Nuerk, H.-C. (2015). Methodological aspects to be considered when measuring the approximate number system (ANS) - a research review. Frontiers in Psychology, 6:295. https://doi.org/10.3389/fpsyg.2015.00295.

Dye, M. W. G., Green, C. S., \& Bavelier, D. (2009a). Increasing speed of processing with action video games. Current Directions in Psychological Science, 18(6), 321-326. https://doi. org/10.1111/j.1467-8721.2009.01660.x.

Dye, M. W. G., Green, C. S., \& Bavelier, D. (2009b). The development of attention skills in action video game players. Neuropsychologia, 47(8-9), 1780-1789. https://doi.org/10.1016/j. neuropsychologia.2009.02.002.

Dykiert, D., Der, G., Starr, J. M., \& Deary, I. J. (2012). Sex differences in reaction time mean and intraindividual variability across the life span. Developmental Psychology, 48(5), 1262-1276. https://doi. org/10.1037/a0027550.

Easdon, C., Izenberg, A., Armilio, M. L., Yu, H., \& Alain, C. (2005). Alcohol consumption impairs stimulus- and error-related processing during a Go/No-Go task. Cognitive Brain Research, 25(3), 873-883. https://doi.org/10.1016/j.cogbrainres.2005.09.009.

Fabbri, M. (2013). Finger counting habits and spatial-numerical association in horizontal and vertical orientations. Journal of Cognition \& Culture, 13(1/2), 95-110. https://doi. org/10.1163/15685373-12342086.

Fischer, M. H. (2008). Finger counting habits modulate spatial-numerical associations. Cortex, 44(4), 386-392. https://doi.org/10.1016/j. cortex.2007.08.004.

Fischer, M. H., \& Shaki, S. (2014). Spatial associations in numerical cognition-from single digits to arithmetic. The Quarterly Journal of Experimental Psychology, 67(8), 1461-1483. https://doi. org/10.1080/17470218.2014.927515.

Ganor-Stern, D., \& Tzelgov, J. (2008). Across-notation automatic numerical processing. Journal of Experimental Psychology: Learning, Memory, and Cognition, 34(2), 430-437. https://doi. org/10.1037/0278-7393.34.2.430.

Ganor-Stern, D., \& Tzelgov, J. (2010). Across-notation automatic processing of two-digit numbers. Experimental Psychology, 58(2), 147-153. https://doi.org/10.1027/1618-3169/a000080. 
Hatta, T., \& Nagaya, K. (2009). Menstrual cycle phase effects on memory and Stroop task performance. Archives of Sexual Behavior, 38(5), 821-827. https://doi.org/10.1007/s10508-008-9445-7.

Hinrichs, J. V., Berie, J. L., \& Mosell, M. K. (1982). Place information in multidigit number comparison. Memory \& Cognition, 10(5), 487-495. https://doi.org/10.3758/BF03197652.

Hinrichs, J. V., Yurko, D. S., \& Hu, J.-M. (1981). Two-digit number comparison: Use of place information. Journal of Experimental Psychology: Human Perception and Performance, 7(4), 890-901.

Holloway, I. D., \& Ansari, D. (2009). Mapping numerical magnitudes onto symbols: the numerical distance effect and individual differences in children's mathematics achievement. Journal of Experimental Child Psychology. https://doi.org/10.1016/j. jecp.2008.04.001.

Huber, S., Klein, E., Graf, M., Nuerk, H.-C., Moeller, K., \& Willmes, K. (2015). Embodied markedness of parity? Examining handedness effects on parity judgments. Psychological Research, 79(6), 963-977. https://doi.org/10.1007/s00426-014-0626-9.

Huber, S., Mann, A., Nuerk, H. C., \& Moeller, K. (2014). Cognitive control in number magnitude processing: evidence from eye-tracking. Psychological Research Psychologische Forschung, 78(4), 539-548. https://doi.org/10.1007/s00426-013-0504-x.

Huber, S., Moeller, K., Nuerk, H.-C., \& Willmes, K. (2013). A computational modeling approach on three-digit number processing. Topics in Cognitive Science, 5(2), 317-334. https://doi. org/10.1111/tops.12016.

Huber, S., Nuerk, H.-C., Willmes, K., \& Moeller, K. (2016). A general model framework for multisymbol number comparison. Psychological Review, 123(6), 667-695. https://doi.org/10.1037/ rev0000040.

Jaeger, T. F. (2008). Categorical data analysis: Away from ANOVAs (transformation or not) and towards logit mixed models. Journal of Memory and Language, 59(4), 434-446. https://doi. org/10.1016/j.jml.2007.11.007.

Kallai, A. Y., \& Tzelgov, J. (2012). The place-value of a digit in multidigit numbers is processed automatically. Journal of Experimental Psychology. Learning, Memory, and Cognition, 38(5), 1221-133.

Killgore, W. D. S. (2010). Effects of sleep deprivation on cognition. In G. A. Kerkhof \& H. P. A. Van Dongen (Eds.), Progress in Brain Research-Human Sleep and Cognition (Vol. 185, pp. 105-129). Amsterdam: Elsevier. https://doi.org/10.1016/ B978-0-444-53702-7.00007-5.

Krantz, J. H., \& Reips, U.-D. (2017). The state of web-based research: A survey and call for inclusion in curricula. Behavior Research Methods, 49(5), 1621-1629.

Kuznetsova, A., Brockhoff, P. B., \& Christensen, R. H. (2016). lmerTest: Tests in linear mixed effects models.

Leys, C., Ley, C., Klein, O., Bernard, P., \& Licata, L. (2013). Detecting outliers: Do not use standard deviation around the mean, use absolute deviation around the median. Journal of Experimental Social Psychology, 49(4), 764-766. https://doi.org/10.1016/j. jesp.2013.03.013.

Lyons, I. M., \& Beilock, S. L. (2011). Numerical ordering ability mediates the relation between number-sense and arithmetic competence. Cognition. https://doi.org/10.1016/j.cognition.2011.07.009.

Macizo, P. (2017). Conflict resolution in two-digit number processing: evidence of an inhibitory mechanism. Psychological research, 81(1), 219-230. https://doi.org/10.1007/s00426-015-0716-3.

Macizo, P., \& Herrera, A. (2011). Cognitive control in number processing: Evidence from the unit-decade compatibility effect. Acta Psychologica, 136(1), 112-118. https://doi.org/10.1016/j. actpsy.2010.10.008.

Macizo, P., \& Herrera, A. (2013). The processing of Arabic numbers is under cognitive control. Psychological Research Psychologische Forschung, 77(5), 651-658. https://doi.org/10.1007/ s00426-012-0456-6.
Macizo, P., Herrera, A., Paolieri, D., \& Román, P. (2010). Is there cross-language modulation when bilinguals process number words? Applied Psycholinguistics, 31(4), 651-669. https://doi. org/10.1017/S0142716410000184.

Macizo, P., Herrera, A., Román, P., \& Martín, M. C. (2011). The processing of two-digit numbers in bilinguals. British Journal of Psychology, 102(3), 464-477. https://doi. org/10.1111/j.2044-8295.2010.02005.x.

Maloney, E. A., Risko, E. F., Preston, F., Ansari, D., \& Fugelsang, J. (2010). Challenging the reliability and validity of cognitive measures: The case of the numerical distance effect. Acta Psychologica, 134(2), 154-161. https://doi.org/10.1016/j.actpsy.2010.01.006.

Moeller, K., Klein, E., \& Nuerk, H. (2013). Influences of cognitive control on numerical cognition-Adaptation by binding for implicit learning. Topics in Cognitive Science, 5, 335-353.

Moeller, K., Pixner, S., Zuber, J., Kaufmann, L., \& Nuerk, H. C. (2011). Early place-value understanding as a precursor for later arithmetic performance - A longitudinal study on numerical development. Research in Developmental Disabilities, 32(5), 1837-1851. https://doi.org/10.1016/j.ridd.2011.03.012.

Moeller, K., Shaki, S., Göbel, S. M., \& Nuerk, H.-C. (2015). Language influences number processing - A quadrilingual study. Cognition, 136(0), 150-155. https://doi.org/10.1016/j.cognition.2014.11.003.

Moyer, R. S., \& Landauer, T. K. (1967). Time required for judgements of numerical inequality. Nature, 215(5109), 1519-1520. https:// doi.org/10.1038/2151519a0.

Norris, J. E., McGeown, W. J., Guerrini, C., \& Castronovo, J. (2015). Aging and the number sense: preserved basic non-symbolic numerical processing and enhanced basic symbolic processing. Frontiers in Psychology, 6, 999. https://doi.org/10.3389/ fpsyg.2015.00999.

Nuerk, H.-C., Moeller, K., Klein, E., Willmes, K., \& Fischer, M. H. (2011). Extending the mental number line: A review of multidigit number processing. Zeitschrift Für Psychologie/Journal of Psychology, 219(1), 3-22.

Nuerk, H.-C., Moeller, K., \& Willmes, K. (2015). Multi-digit number processing - Overview, conceptual clarifications, and language influences. In R. C. Kadosh \& A. Dowker (Eds.), The Oxford Handbook of Numerical Cognition (pp. 106-139). Oxford: Oxford University Press.

Nuerk, H.-C., Weger, U., \& Willmes, K. (2001). Decade breaks in the mental number line? Putting the tens and units back in different bins. Cognition, 82(1), B25-B33. https://doi.org/10.1016/ S0010-0277(01)00142-1.

Nuerk, H.-C., Weger, U., \& Willmes, K. (2005). Language effects in magnitude comparison: Small, but not irrelevant. Brain and Language, 92(3), 262-277. https://doi.org/10.1016/j. band1.2004.06.107.

Nys, J., Ventura, P., Fernandes, T., Querido, L., Leybaert, J., \& Content, A. (2013). Does math education modify the approximate number system? A comparison of schooled and unschooled adults. Trends in Neuroscience and Education, 2(1), 13-22. https://doi. org/10.1016/j.tine.2013.01.001.

Patro, K., Nuerk, H.-C., \& Cress, U. (2015). Does your body count? Embodied influences on the preferred counting direction of preschoolers. Journal of Cognitive Psychology, 27(4), 413-425. https://doi.org/10.1080/20445911.2015.1008005.

Pixner, S., Moeller, K., Hermanova, V., Nuerk, H. C., \& Kaufmann, L. (2011). Whorf reloaded: Language effects on nonverbal number processing in first grade-A trilingual study. Journal of Experimental Child Psychology, 108(2), 371-382. https://doi. org/10.1016/j.jecp.2010.09.002.

Pletzer, B., Kronbichler, M., Nuerk, H.-C., \& Kerschbaum, H. (2014). Hormonal contraceptives masculinize brain activation patterns in the absence of behavioral changes in two numerical tasks. 
Brain Research, 1543, 128-142. https://doi.org/10.1016/j. brainres.2013.11.007.

Prior, A., Katz, M., Mahajna, I., \& Rubinsten, O. (2015). Number word structure in first and second language influences arithmetic skills. Frontiers in Psychology, 6, 266. https://doi.org/10.3389/ fpsyg.2015.00266.

Ratcliff, R. (1993). Methods for dealing with reaction time outliers. Psychological Bulletin, 114(3), 510-532. https://doi. org/10.1037/0033-2909.114.3.510.

Ratinckx, E., Nuerk, H.-C., van Dijck, J. P., \& Willmes, K. (2006). Effects of interhemispheric communication on two-digit arabic number processing. Cortex, 42(8), 1128-1137. https://doi. org/10.1016/S0010-9452(08)70225-9.

Reips, U.-D. (2002). Standards for Internet-based experimenting. Experimental Psychology, 49(4), 243-256. https://doi. org/10.1026//1618-3169.49.4.243.

Reips, U.-D. (2007). The methodology of Internet-based experiments. In A. Joinson, K. McKenna, T. Postmes \& U.-D. Reips (Eds.), The Oxford Handbook of Internet Psychology (pp. 373-390). Oxford: Oxford University Press.

Reips, U.-D. (2012). The methodology of Internet-based experiments. In A. N. Joinson, K. Y. A. McKenna, T. Postmes \& U.-D. Reips (Eds.), Oxford Handbook of Internet Psychology (pp. 373-390). Oxford: Oxford University Press.

Reips, U.-D., \& Lengler, R. (2005). The Web Experiment List: A Web service for the recruitment of participants and archiving of Internet-based experiments. Behavior Research Methods, 37, 287-292.

Reips, U.-D., \& Neuhaus, C. (2002). WEXTOR: A Web-based tool for generating and visualizing experimental designs and procedures. Behavior Research Methods, 34(2), 234-240.

Reuter-Lorenz, P. A., \& Park, D. C. (2010). Human neuroscience and the aging mind: A new look at old problems. The Journals of Gerontology Series B: Psychological Sciences and Social Sciences. https://doi.org/10.1093/geronb/gbq035.

Roberts, G. M. P., Newell, F., Simões-Franklin, C., \& Garavan, H. (2008). Menstrual cycle phase modulates cognitive control over male but not female stimuli. Brain Research, 1224, 79-87. https:// doi.org/10.1016/j.brainres.2008.05.061.

Salthouse, T. A. (1996). The processing-speed theory of adult age differences in cognition. Psychological Review, 103(3), 403-428. https://doi.org/10.1037/0033-295X.103.3.403.

Schneider, M., Beeres, K., Coban, L., Merz, S., Susan Schmidt, S., Stricker, J., \& De Smedt, B. (2016). Associations of non-symbolic and symbolic numerical magnitude processing with mathematical competence: a meta-analysis. Developmental Science. https://doi. org/10.1111/desc. 12372 .
Singmann, H., Bolker, B., Westfall, J., \& Aust, F. (2016). afex: Analysis of Factorial Experiments.

Steinborn, M. B., Bratzke, D., Rolke, B., Gordijn, M. C. M., Beersma, D. G. M., \& Ulrich, R. (2010). The effect of $40 \mathrm{~h}$ of constant wakefulness on number comparison performance. Chronobiology International: The Journal of Biological \& Medical Rhythm Research, 27(4), 807-825.

Stroop, J. R. (1935). Studies of interference in serial verbal reactions. Journal of Experimental Psychology, 18(6), 643-662.

Thomas, M., \& Morwitz, V. (2005). Penny wise and pound foolish: The left-digit effect in price cognition. Journal of Consumer Research, 32(1), 54-64.

Van Opstal, F., \& Verguts, T. (2011). The origins of the numerical distance effect: The same-different task. Journal of Cognitive Psychology, 23(1), 112-120.

Van Rinsveld, A., \& Schiltz, C. (2016). Sixty-twelve = Seventy-two? A cross-linguistic comparison of children's number transcoding. British Journal of Developmental Psychology, 34(3), 461-468. https://doi.org/10.1111/bjdp.12151.

Van Rinsveld, A., Schiltz, C., Landerl, K., Brunner, M., \& Ugen, S. (2016). Speaking two languages with different number naming systems: What implications for magnitude judgments in bilinguals at different stages of language acquisition? Cognitive Processing, 17(3), 225-241. https://doi.org/10.1007/s10339-016-0762-9.

Verguts, T., Fias, W., \& Stevens, M. (2005). A model of exact smallnumber representation. Psychonomic Bulletin \& Review, 12(1), 66-80. https://doi.org/10.3758/Bf03196349.

Verguts, T., \& Notebaert, W. (2009). Adaptation by binding: a learning account of cognitive control. Trends in cognitive sciences, 13(6), 252-257.

Whelan, R. (2010). Effective analysis of reaction time data. The Psychological Record, 58(3), 475-482.

Wickham, H. (2009). ggplot2: Elegant graphics for data analysis. Springer-Verlag, New York.

Wilke, C. O. (2016). cowplot: Streamlined plot theme and plot annotations for ggplot2.

Wood, G., Nuerk, H. C., Freitas, P., Freitas, G., \& Willmes, K. (2006). What do semi-illiterate adults know about 2-digit arabic numbers? Cortex, 42(1), 48-56. https://doi.org/10.1016/ S0010-9452(08)70321-6.

Zebian, S., \& Ansari, D. (2012). Differences between literates and illiterates on symbolic but not nonsymbolic numerical magnitude processing. Psychonomic Bulletin \& Review, 19(1), 93-100. https://doi.org/10.3758/s13423-011-0175-9. 